\title{
The complete genome sequence of the Gram-positive bacterium Bacillus subtilis
}

F. Kunst ${ }^{1}$, N. Ogasawara ${ }^{2}$, I. Moszer ${ }^{3}$, A. M. Albertini ${ }^{4}$, G. Alloni ${ }^{4}$, V. Azevedo ${ }^{5}$, M. G. Bertero ${ }^{3,4}$, P. Bessières ${ }^{5}$, A. Bolotin ${ }^{5}$, S. Borchert ${ }^{6}$, R. Borriss ${ }^{7}$, L. Boursier ${ }^{3}$, A. Brans ${ }^{8}$, M. Braun ${ }^{9}$, S. C. Brignell ${ }^{10}$, S. Bron ${ }^{11}$, S. Brouillet ${ }^{3,12}$, C. V. Bruschi ${ }^{13}$, B. Caldwell ${ }^{14}$, V. Capuano $^{5}$, N. M. Carter ${ }^{10}$, S.-K. Choi ${ }^{15}$, J.-J. Codani ${ }^{16}$, I. F. Connerton ${ }^{17}$, N. J. Cummings ${ }^{17}$, R. A. Daniel ${ }^{18}$, F. Denizot ${ }^{19}$, K. M. Devine ${ }^{20}$, A. Düsterhöft $^{9}$, S. D. Ehrlich ${ }^{5}$, P. T. Emmerson ${ }^{21}$, K. D. Entian ${ }^{6}$, J. Errington ${ }^{18}$, C. Fabret $^{19}$, E. Ferrari $^{14}$, D. Foulger $^{18}$, C. Fritz $^{9}$, M. Fujita ${ }^{22}$, Y. Fujita $^{23}$, S. Fuma $^{24}$, A. Galizzi ${ }^{4}$, N. Galleron ${ }^{5}$, S.-Y. Ghim ${ }^{15}$, P. Glaser ${ }^{3}$, A. Goffeau ${ }^{25}$, E. J. Golightly ${ }^{26}$, G. Grandi ${ }^{27}$, G. Guiseppi ${ }^{19}$, B. J. Guy ${ }^{10}$, K. Haga ${ }^{28}$, J. Haiech ${ }^{19}$, C. R. Harwood ${ }^{10}$, A. Hénaut ${ }^{29}$, H. Hilbert ${ }^{9}$, S. Holsappel ${ }^{11}$, S. Hosono ${ }^{30}$, M.-F. Hullo ${ }^{3}$, M. Itaya ${ }^{31}$, L. Jones ${ }^{32}$, B. Joris ${ }^{8}$, D. Karamata ${ }^{33}$, Y. Kasahara ${ }^{2}$, M. Klaerr-Blanchard ${ }^{3}$, C. Klein ${ }^{6}$, Y. Kobayashi ${ }^{30}$, P. Koetter ${ }^{6}$, G. Koningstein ${ }^{34}$, S. Krogh ${ }^{20}$, M. Kumano ${ }^{24}$, K. Kurita $^{24}$, A. Lapidus ${ }^{5}$, S. Lardinois ${ }^{8}$, J. Lauber', V. Lazarevic ${ }^{33}$, S.-M. Lee ${ }^{35}$, A. Levine $^{36}$, H. Liu $^{28}$, S. Masuda ${ }^{30}$, C. Mauël $^{33}$, C. Médigue $^{3,12}$, N. Medina ${ }^{36}$, R. P. Mellado ${ }^{37}$, M. Mizuno ${ }^{30}$, D. Moest $\left.\right|^{9}$, S. Nakai ${ }^{2}$, M. Noback ${ }^{11}$, D. Noone ${ }^{20}$, M. O'Reilly ${ }^{20}$, K. Ogawa $^{24}$, A. Ogiwara ${ }^{38}$, B. Oudega ${ }^{34}$, S.-H. Park ${ }^{15}$, V. Parro ${ }^{37}$, T. M. Pohl ${ }^{39}$, D. Portetelle ${ }^{40}$, S. Porwollik ${ }^{7}$, A. M. Prescott ${ }^{18}$, E. Presecan ${ }^{3}$, P. Pujic ${ }^{5}$, B. Purnelle ${ }^{25}$, G. Rapoport ${ }^{1}$, M. Rey $^{26}$, S. Reynolds ${ }^{33}$, M. Rieger ${ }^{41}$, C. Rivolta ${ }^{33}$, E. Rocha ${ }^{3,12}$, B. Roche ${ }^{36}$, M. Rose ${ }^{6}$, Y. Sadaie ${ }^{22}$, T. Sato ${ }^{30}$, E. Scanlan $^{20}$, S. Schleich ${ }^{3}$, R. Schroeter ${ }^{7}$, F. Scoffone ${ }^{4}$, J. Sekiguchi ${ }^{42}$, A. Sekowska ${ }^{3}$, S. J. Seror ${ }^{36}$, P. Serror ${ }^{5}$, B.-S. Shin ${ }^{15}$, B. Soldo ${ }^{33}$, A. Sorokin ${ }^{5}$, E. Tacconi ${ }^{4}$, T. Takagi ${ }^{43}$, H. Takahashi ${ }^{28}$, K. Takemaru ${ }^{30}$, M. Takeuchi ${ }^{30}$, A. Tamakoshi ${ }^{24}$, T. Tanaka ${ }^{44}$, P. Terpstra ${ }^{11}$, A. Tognoni $^{27}$, V. Tosato ${ }^{13}$, S. Uchiyama ${ }^{42}$,

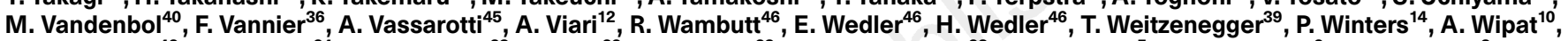
H. Yamamoto ${ }^{42}$, K. Yamane ${ }^{24}$, K. Yasumoto ${ }^{28}$, K. Yata ${ }^{22}$, K. Yoshida ${ }^{23}$, H.-F. Yoshikawa ${ }^{28}$, E. Zumstein ${ }^{5}$, H. Yoshikawa ${ }^{2}$ \& A. Danchin ${ }^{3}$

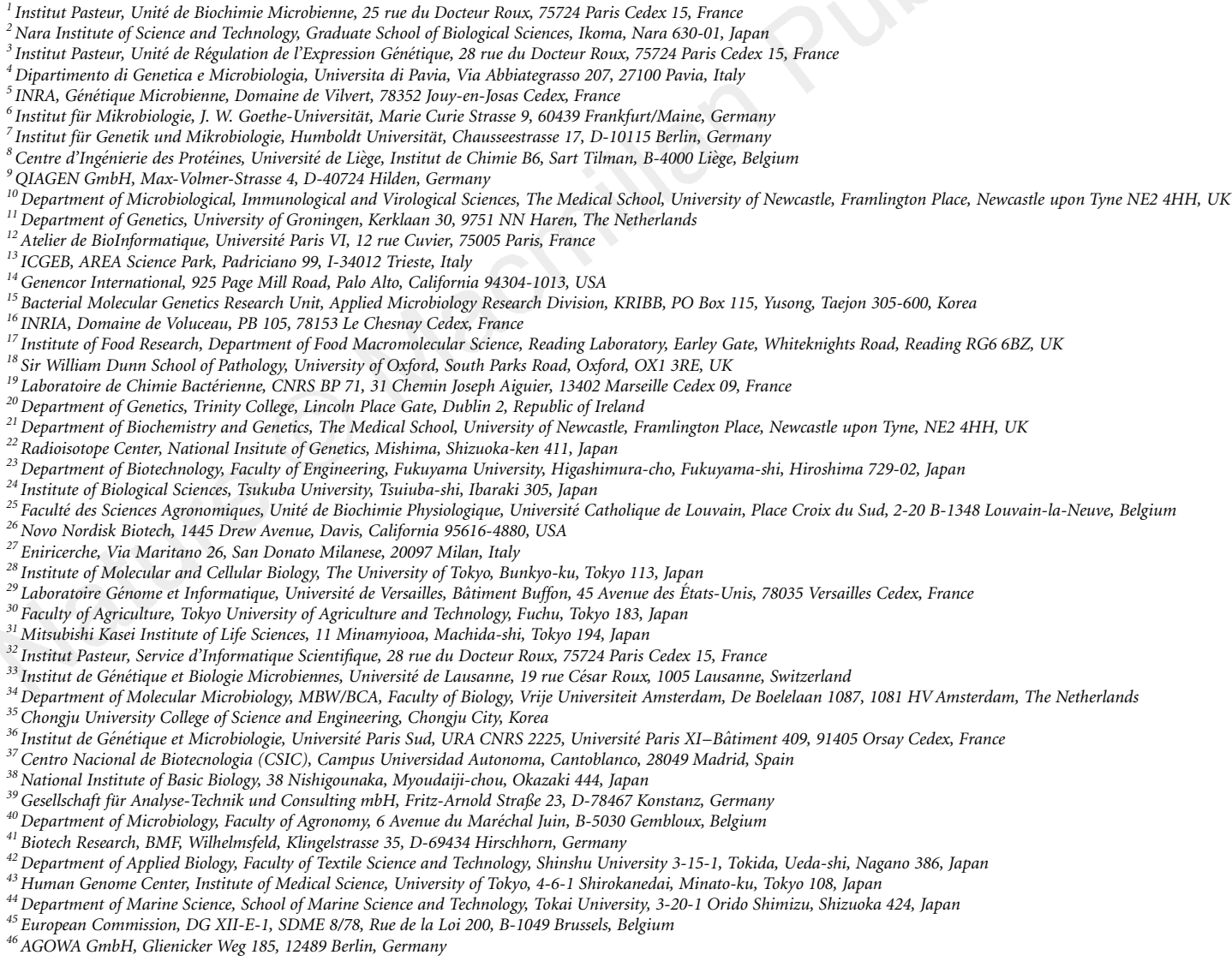

Bacillus subtilis is the best-characterized member of the Gram-positive bacteria. Its genome of 4,214,810 base pairs comprises 4,100 protein-coding genes. Of these protein-coding genes, $53 \%$ are represented once, while a quarter of the genome corresponds to several gene families that have been greatly expanded by gene duplication, the largest family containing 77 putative ATP-binding transport proteins. In addition, a large proportion of the genetic capacity is devoted to the utilization of a variety of carbon sources, including many plant-derived molecules. The identification of five signal peptidase genes, as well as several genes for components of the secretion apparatus, is important given the capacity of Bacillus strains to secrete large amounts of industrially important enzymes. Many of the genes are involved in the synthesis of secondary metabolites, including antibiotics, that are more typically associated with Streptomyces species. The genome contains at least ten prophages or remnants of prophages, indicating that bacteriophage infection has played an important evolutionary role in horizontal gene transfer, in particular in the propagation of bacterial pathogenesis. 
Techniques for large-scale DNA sequencing have brought about a revolution in our perception of genomes. Together with our understanding of intermediary metabolism, it is now realistic to envisage a time when it should be possible to provide an extensive chemical definition of many living organisms. During the past couple of years, the genome sequences of Haemophilus influenzae, Mycoplasma genitalium, Synechocystis PCC6803, Methanococcus jannaschii, M. pneumoniae, Escherichia coli, Helicobacter pylori, Archaeoglobus fulgidus and the yeast Saccharomyces cerevisiae have been published in their entirety ${ }^{1-8}$, and at least 40 prokaryotic genomes are currently being sequenced. Regularly updated lists of genome sequencing projects are available at http://www.mcs.anl. gov/home/gaasterl/genomes.html (Argonne National Laboratory, Illinois, USA) and http://www.tigr.org (TIGR, Rockville, Maryland, USA).

The list of sequenced microorganisms does not currently include a paradigm for Gram-positive bacteria, which are known to be important for the environment, medicine and industry. Bacillus subtilis has been chosen to fill this gap $^{9,10}$ as its biochemistry, physiology and genetics have been studied intensely for more than 40 years. B. subtilis is an aerobic, endospore-forming, rodshaped bacterium commonly found in soil, water sources and in association with plants. B. subtilis and its close relatives are an important source of industrial enzymes (such as amylases and proteases), and much of the commercial interest in these bacteria arises from their capacity to secrete these enzymes at gram per litre concentrations. It has therefore been used for the study of protein secretion and for development as a host for the production of heterologous proteins ${ }^{11}$. B. subtilis (natto) is also used in the production of Natto, a traditional Japanese dish of fermented soya beans.

Under conditions of nutritional starvation, B. subtilis stops growing and initiates responses to restore growth by increasing metabolic diversity. These responses include the induction of motility and chemotaxis, and the production of macromolecular hydrolases (proteases and carbohydrases) and antibiotics. If these responses fail to re-establish growth, the cells are induced to form chemically, irradiation- and desiccation-resistant endospores. Sporulation involves a perturbation of the normal cell cycle and the differentiation of a binucleate cell into two cell types. The division of the cell into a smaller forespore and a larger mother cell, each with an entire copy of the chromosome, is the first morphological indication of sporulation. The former is engulfed by the latter and differential expression of their respective genomes, coupled to a complex network of interconnected regulatory path- ways and developmental checkpoints, culminates in the programmed death and lysis of the mother cell and release of the mature spore ${ }^{12}$. In an alternative developmental process, B. subtilis is also able to differentiate into a physiological state, the competent state, that allows it to undergo genetic transformation ${ }^{13}$.

\section{General features of the DNA sequence}

Analysis at the replicon level. The B. subtilis chromosome has $4,214,810$ base pairs (bp), with the origin of replication coinciding with the base numbering start point ${ }^{14}$, and the terminus at about 2,017 kilobases $(\mathrm{kb})^{15}$. The average $\mathrm{G}+\mathrm{C}$ ratio is $43.5 \%$, but it varies considerably throughout the chromosome. This average is also different if one considers the nucleotide content of coding sequences, for which $\mathrm{G}$ and $\mathrm{A}(24 \%$ and $30 \%)$ are relatively more abundant than their counterparts $\mathrm{C}$ and $\mathrm{T}(20 \%$ and $26 \%)$. A significant inversion of the relative $\mathrm{G}-\mathrm{C} / \mathrm{G}+\mathrm{C}$ ratio is visible at the origin of replication, indicating asymmetry of the nucleotide composition between the replication leading strand and the lagging strand $^{16}$. Several A + T-rich islands are likely to reveal the signature of bacteriophage lysogens or other inserted elements (Fig. 1, see below).

We have analysed the abundance of oligonucleotides ('words') in the genome in various ways: absolute number of words in the genomic text, or comparison with the expected count derived from several models of the chromosome (for example, Markov models, or simulated sequences in which previously known features of the genome were conserved ${ }^{17}$ ). Comparing the experimental data with various models allowed us to define under- and overrepresentation of words in the experimental data set by reference to the model chosen. In general, the dinucleotide bias follows closely what has been described for other prokaryotes ${ }^{18,19}$, in that the dinucleotides most overrepresented are AA, TT and GC, whereas those less represented are TA, AC and GT. Plots of the frequencies of AG, GA, CT and TC in sliding windows along the chromosome show dramatic decreases or increases around the origin and terminus of replication (data not shown). Trinucleotide frequency, directly related to the coding frame, will be discussed below. The distribution of words of four, five and six nucleotides shows significant correlations between the usage of some words and replication (several such oligonucleotides are very significantly overrepresented in one of the strands and underrepresented in the other one).

Setting a statistical cut-off for the significance of duplications at $10^{-3}$, we expected duplication by chance of words longer than 24 nucleotides to be rare ${ }^{20}$. In fact, the genome of $B$. subtilis contains a plethora of such duplications, some of them appearing more than

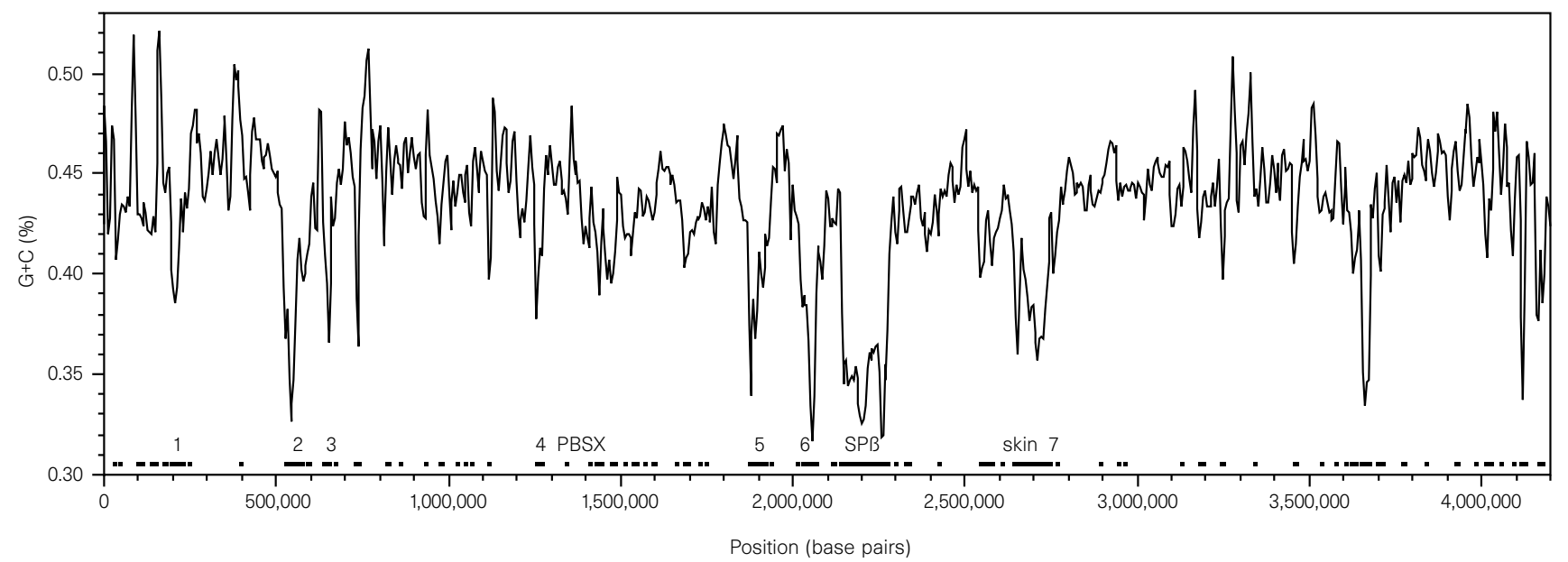

Figure 1 Distribution of $A+T$-rich islands along the chromosome of $B$. subtilis, in sliding windows of 10,000 nucleotides, with a step of 5,000 nucleotides. Location of genes from class 3 according to codon usage analysis (see Fig. 4) is indicated

by dots at the bottom of the graph. Known prophages (PBSX, SP $\beta$ and skin) are indicated by their names, and prophage-like elements are numbered from 1 to 7 . 
twice. Among the duplications, we identified, as expected, the ribosomal RNA genes and their flanking regions, but also regions known to correspond to genes comprising long sequence repeats (such as $p k s$ and $s r f$ ). We also found several regions that were not expected: a 182-bp repetition within the yyaL and yyaO genes; a 410-bp repetition between the $y x a K$ and $y x a L$ genes; an internal duplication of $174 \mathrm{bp}$ inside $y d c I$; and significant duplications in the regions involved in the transcriptional control of several genes (such as $118 \mathrm{bp}$ repeated three times between $y \times b B$ and $y x b C$ ). Finally, we found several repetitions at the borders of regions that might be involved in bacteriophage integration.

The most prominent duplication was a 190-bp element that was repeated 10 times in the chromosome. Multiple alignment of the ten repeats showed that they could be classified into two subfamilies with six and three copies each, plus a copy of what appears to be a chimaera. Similar sequences have also been described in the closely related species Bacillus licheniformis ${ }^{21,22}$. A striking feature of these repeats is that they are only found in half of the chromosome, at either side of the origin of replication, with five repeats on each side. Furthermore, with the exception of the most distal repeat at position 737,062, they lie in the same orientation with respect to the movement of the replication fork (Figs 2 and 3). Putative secondary structures conserved by compensatory mutations, as well as an insert in three of the copies, suggest that this element could indicate a structural RNA molecule.

Analysis at the transcription and translation level. Over 4,000 putative protein coding sequences (CDSs) have been identified, with an average size of $890 \mathrm{bp}$, covering $87 \%$ of the genome sequence (Fig. 2). We found that $78 \%$ of the genes started with ATG, $13 \%$ with TTG and $9 \%$ with GTG, which compares with $85 \%$, $3 \%$ and $14 \%$, respectively, in E. coli ${ }^{8}$. Fifteen genes (eight in the predicted CDSs in bacteriophage $\operatorname{SP} \beta$ ) exhibiting unusual start codons (namely ATT and CTG) were also identified through their

Table 1 Functional classification of the Bacillus subtilis protein-coding genes

The genes of known function or encoding products similar to known proteins in $B$. subtilis or in other organisms have been classified into functional categories (2,379 genes). The total number of genes in each category is indicated after the category title. Genes are listed in alphabetical order within each category, and their positions (in kilobases) on the $B$. subtilis chromosome are indicated after the gene names. A brief description is given for each gene. In some cases, interacting proteins have been indicated between brackets (for example, histidine kinases and response regulator, phosphatases and their substrates). More detailed and constantly updated information is available in the SubtiList database (see Methods). A preliminary assessment of the significance of sequence similarities was obtained through an automated procedure involving a combination between the BLAST2P probability and the percentage of amino-acid identity. Matches considered significant were re-examined manually. It should be emphasized that functions assigned to ' $y$ ' genes are based only on sequence similarity information with the best counterparts in protein databanks. Genes whose products are only similar to other unknown proteins, or not significantly similar to any other proteins in databanks (categories V and VI), were omitted.

Figure 2 General view of the B. subtilis chromosome. Arrows indicate the orientation of transcription. Genes are coloured according to their classification into six broad functional categories (blue, category I; green, category II; red, category III; orange, category IV; purple, category V; pink, category VI; see Table 1). Class 2 CDSs according to codon usage analysis are indicated by oblique hatches, and class 3 CDSs are indicated by vertical hatches. Ribosomal RNA genes are coloured in yellow. Transfer RNA genes are marked by triangles. Other RNA genes are represented as white arrows. Known genes (non-' $y$ ' genes) are printed in bold type. Putative transcription termination sites are represented as loops. Known prophages and prophage-like elements are indicated by brown hatches on the chromosome line. The 190-bp element repeated ten times is represented by hatched boxes. similarities to known genes in other organisms or because they had a good GeneMark prediction (see Methods). This has not yet been substantiated experimentally. However, in the case of the gene coding for translation initiation factor 3, the similarity with its $E$. coli counterpart strongly suggests that the initiation codon is ATT, as is the case in E. coli.

We have not annotated CDSs that largely or entirely overlap existing genes, although such genes (for example, coms inside $\operatorname{srf} A A$ ) certainly exist. It is also likely that some of the short CDSs present in the B. subtilis genome have been overlooked. For these reasons and possible sequencing errors, the estimated number of $B$. subtilis CDSs will fluctuate around the present figure of 4,100 .

In several cases, in-frame termination codons or frameshifts were confirmed to be present on the chromosome (for example, an internal termination codon in $y w t F$, or the known programmed translational frameshift in $\operatorname{prf} B$ ), indicating that the genes are either non-functional (pseudogenes) or subject to regulatory processes. It will therefore be of interest to determine whether these gene features are conserved in related Bacillus species, especially as strain 168 is derived from the Marburg strain that was subjected to X-ray irradiation $^{23}$.

A few regions do not have any identifiable feature indicating that they are transcribed: they could be 'grey holes' of the type described in E. coli $^{24}$. Preliminary studies involving all regions of more than $400 \mathrm{bp}$ without annotated CDSs indicated that, of $\sim 300$ such regions, only $15 \%$ were likely to be really devoid of proteincoding sequences. One of the longest such regions, located between $y f j O$ and $y f j N$, is 1,628 bp long. Grey holes seem generally to be clustered near the terminus of replication. However, a grey-hole cluster located at $\sim 600 \mathrm{~kb}$ might be related to the temporary chromosome partition observed during the first stages of sporulation, when a segment of about one-third of the chromosome enters the prespore, and remains the sole part of the chromosome in the prespore for a significant transition period ${ }^{25}$.

The codon usage of $B$. subtilis CDSs was analysed using factorial correspondence analysis ${ }^{17}$. We found that the CDSs of B. subtilis could be separated into three well-defined classes (Fig. 4). Class 1 comprises the majority of the B. subtilis genes (3,375 CDSs), including most of the genes involved in sporulation. Class 2 (188 CDSs) includes genes that are highly expressed under exponential growth conditions, such as genes encoding the transcription and translation machineries, core intermediary metabolism, stress proteins, and one-third of genes of unknown function. Class 3 (537 CDSs) contains a very high proportion of genes of unidentified function $(84 \%)$, and the members of this class have codons enriched in $\mathrm{A}+\mathrm{T}$ residues. These genes are usually clustered into groups between 15 and 160 genes (for example, bacteriophage SP $\beta$ ) and correspond to the A $+\mathrm{T}$-rich islands described above (Fig. 1). When they are of known function, or when their products display similarity to proteins of known function, they usually correspond to functions found in, or associated with, bacteriophages or transposons, as well as functions related to the cell envelope. This includes the region $y d c / y d d / y d e$ (40 genes that are missing in some B. subtilis strain ${ }^{26}$ ), where gene products showing similarities to bacteriophage and transposon proteins are intertwined. Many of these genes are associated with virulence genes identified in pathogenic Gram-positive bacteria, suggesting that such virulence factors are transmitted horizontally among bacteria at a much higher frequency than previously thought. If we include these A + T-rich regions as possible cryptic phages, together with known bacteriophages or bacteriophage-like elements ( $\mathrm{SP} \beta, \mathrm{PBSX}$ and the skin element), we find that the genome of $B$. subtilis 168 contains at least 10 such elements (Figs 2 and 3). Annotation of the corresponding regions often reveals the presence of genes that are similar to bacteriophage lytic enzymes, perhaps accounting for the observation that $B$. subtilis cultures are extremely prone to lysis.

The ribosomal RNA genes have been previously identified and 
shown to be organized into ten rRNA operons, mainly clustered around the origin of replication of the chromosome (Figs 2 and 3 ). In addition to the 84 previously identified tRNA genes, by using the Palingol $^{27}$ and tRNAscan ${ }^{28}$ programs, we propose four putative new tRNA loci (at 1,262 kb, 1,945 kb, 2,003 kb and 2,899 kb), specific for lysine, proline and arginine (UUU, GGG, CCU and UCU anticodons, respectively). The 10S RNA involved in degradation of proteins made from truncated mRNA has been identified ( $s s r A$ ), as well as the RNA component of RNase P $(r n p B)$ and the 4.5S RNA involved in the secretion apparatus $(s c r)$.

There is a strong transcription orientation bias with respect to the movement of the replication fork: $75 \%$ of the predicted genes are transcribed in the direction of replication. Plotting the density of coding nucleotides in each strand along the chromosome readily identifies the replication origin and terminus (Fig. 3). To identify putative operons, we followed ref. 29 for describing Rhoindependent transcription termination sites. This yielded $\sim 1,630$ putative terminators ( 340 of which were bidirectional). We retained only those that were located less than $100 \mathrm{bp}$ downstream of a gene, or that were considered by the program to be 'very strong' (in order to account for possible erroneous CDSs). This yielded a total of $\sim 1,250$ terminators, with a mean operon size of three genes. A similar approach to the identification of promoters is problematical, especially because at least 14 sigma factors, recognizing different promoter sequences, have been identified in B. subtilis. Nevertheless, the consensus of the main vegetative sigma factor $\left(\sigma^{\mathrm{A}}\right)$ appears to be identical to its counterpart in E. coli $\left(\sigma^{70}\right): 5^{\prime}$ TTGACA- $n_{17}$-TATAAT- $3^{\prime}$. Relaxing the constraints of the similarity to sigma-specific consensus sequences led to an extremely high number of false-positive results, suggesting that the consensusoriented approach to the identification of promoters should be replaced by another approach ${ }^{17}$.

\section{Classification of gene products}

Genes were classified according to ref. 14, based on the representation of cells as Turing machines in which one distinguishes between the machine and the program (Table 1). Using the BLAST2P software running against a composite protein databank compound of SWISS-PROT (release 34), TREMBL (release 3, update 1) and $B$. subtilis proteins, we assigned at least one significant counterpart with a known function to $58 \%$ of the B. subtilis proteins. Thus for up to $42 \%$ of the gene products, the function cannot be predicted by similarity to proteins of known function: $4 \%$ of the proteins are similar only to other unknown proteins of B. subtilis; $12 \%$ are similar to unknown proteins from some other organism; and $26 \%$ of the proteins are not significantly similar to any other proteins in databanks. This preliminary analysis should be interpreted with caution, because only $\sim 1,200$ gene functions $(30 \%)$ have been experimentally identified in $B$. subtilis. We used the ' $y$ ' prefix in gene names to emphasize that the function has not been ascertained (2,853 ' $y$ ' genes, representing $70 \%)$.

Regulatory systems. Transcription regulatory proteins. Helixturn-helix proteins form a large family of regulatory proteins found in both prokaryotes and eukaryotes. There are several classes, including repressors, activators and sigma factors. Using BLAST searches, we constructed consensus matrices for helix-turn-helix proteins to analyse the B. subtilis protein library. We identified 18 sigma or sigma-like factors, of which nine (including a new one) are of the SigA type. We also putatively identified 20 regulators (among which 18 were products of ' $y$ ' genes) of the GntR family, 19 regulators ( 15 ' $y$ ' genes) of the LysR family, and 12 regulators (5 ' $y$ ' genes) of the LacI family. Other transcription regulatory proteins were of the AraC family ( 11 members, 10 ' $y$ '), the Lrp family ( 7 members, 3 ' $y$ '), the DeoR family (6 members, 3 ' $y$ '), or additional families (such as the MarR, ArsR or TetR families). A puzzling observation is that several regulatory proteins display significant similarity to aminotransferases (seven such enzymes have been identified as showing similarity to repressors).

Two-component signal-transduction pathways. Two-component regulatory systems, consisting of a sensor protein kinase and a response regulator, are widespread among prokaryotes. We have identified 34 genes encoding response regulators in $B$. subtilis, most of which have adjacent genes encoding histidine kinases. Response regulators possess a well-conserved $\mathrm{N}$-terminal phospho-acceptor domain $^{30}$, whereas their C-terminal DNA-binding domains share similarities with previously identified response regulators in E. coli, Rhizobium meliloti, Klebsiella pneumoniae or Staphylococcus aureus. Representatives of the four subfamilies recently identified in E. coli ${ }^{31}$

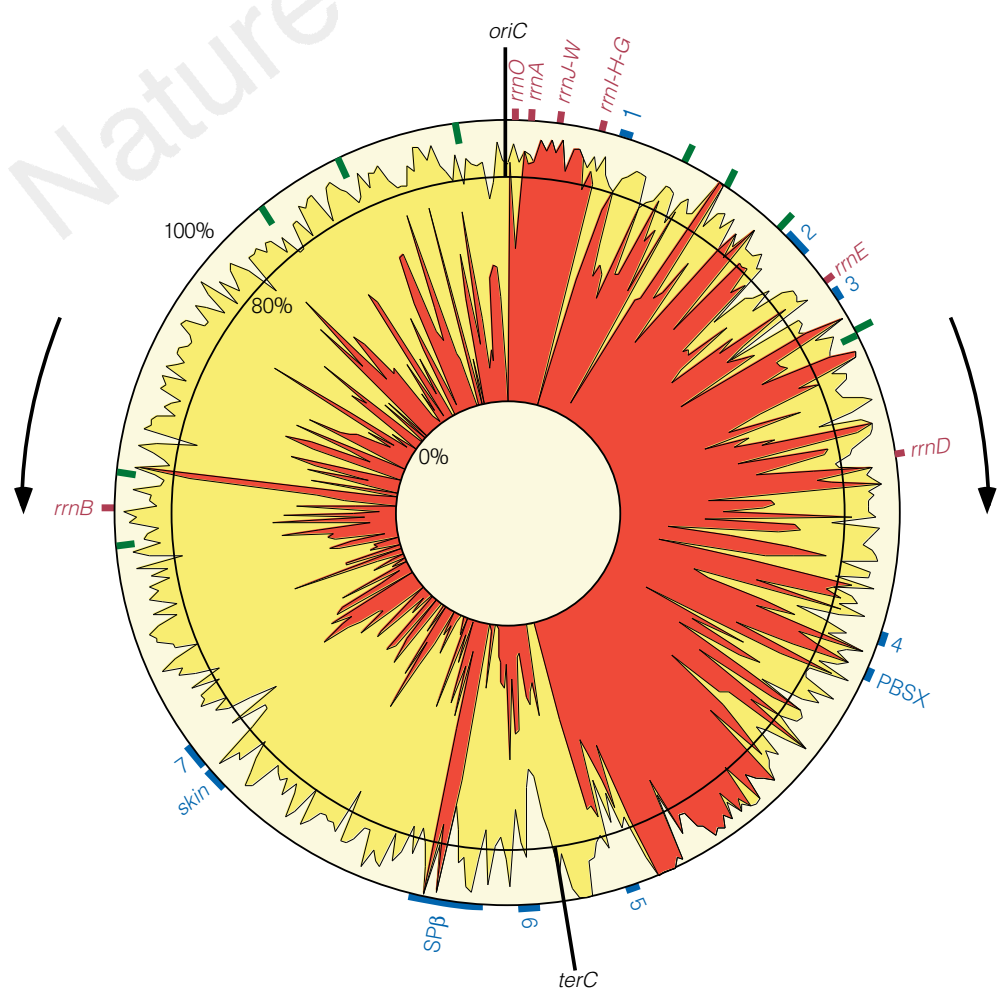

Figure 3 Density of coding nucleotides along the B. subtilis chromosome. Yellow stands for the density of coding nucleotides in both strands of the sequence; red indicates the density of coding nucleotides in the clockwise strand (nucleotides involved in genes transcribed in the clockwise orientation). The movement of the replication forks is represented by arrows. Ribosomal RNA operons are indicated by brown boxes. Known prophages and prophage-like elements are represented as blue lines. The 190-bp element repeated ten times is represented by green lines. 


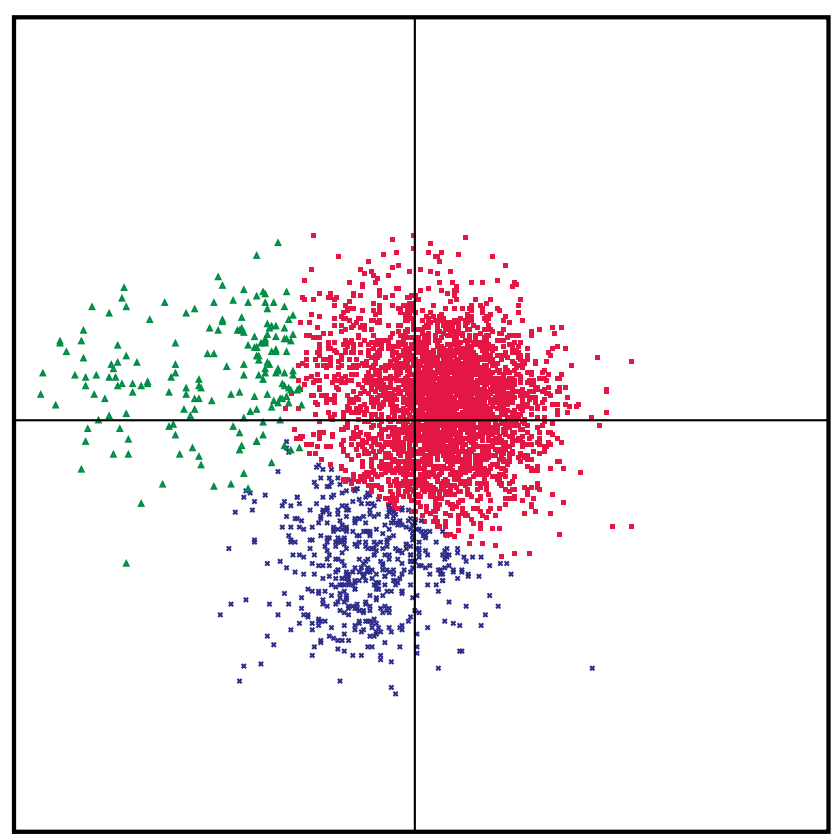

Figure 4 Factorial correspondence analysis of codon usage in the $B$. subtilis CDSs. Red dots, genes from class 1; green triangles, genes from class 2; blue crosses, genes from class 3 . Class 2 contains genes coding for the translation and transcription machineries, and genes of the core intermediary metabolism. Class 3 genes correspond to codons strongly enriched in A or $\mathrm{T}$ in the wobble position; they generally belong to prophage-like inserts in the genome.

(OmpR, FixJ, CitB and LytR) have been identified in B. subtilis. In a fifth subfamily, CheY, the DNA-binding domain is absent. The DNA-binding domain of a single $B$. subtilis response regulator, YesN, shares similarity with regulatory proteins of the AraC family. Quorum sensing. The B. subtilis genome contains 11 aspartate phosphatase genes, whose products are involved in dephosphorylation of response regulators, that do not seem to have counterparts in Gram-negative bacteria such as E. coli. Downstream from the corresponding genes are some small genes, called $p h r$, encoding regulatory peptides that may serve as quorum sensors ${ }^{32}$. Seven $p h r$ genes have been identified so far, including three new genes ( $p h r G$, phrI and phrK).
Protein secretion. It is known that B. subtilis and related Bacillus species, in particular B. licheniformis and B. amyloliquefaciens, have a high capacity to secrete proteins into the culture medium. Several genes encoding proteins of the major secretion pathway have been identified: $\sec A, \sec D, \sec E, \sec F, \sec Y$, ffh and ftsY. Surprisingly, there is no gene for the $\mathrm{Sec} B$ chaperone. It is thought that other chaperone(s) and targeting factor(s), such as Ffh and FtsY, may take over the SecB function. Further, although there is only one such gene in E. coli, five type I signal peptidase genes ( $\operatorname{sipS}$, sipT, sipU, sipV and sip $W$ ) have been found ${ }^{33}$. The lsp gene, encoding a type II signal peptidase required for processing of lipo-modified precursors, was also identified. PrsA, located at the outer side of the membrane, is important for the refolding of several mature proteins after their translocation through the membrane.

Other families of proteins. $\mathrm{ABC}$ transporters were the most frequent class of proteins found in B. subtilis. They must be extremely important in Gram-positive bacteria, because they have an envelope comprising a single membrane. $\mathrm{ABC}$ transporters will therefore allow such bacteria to escape the toxic action of many compounds. We propose that 77 such transporters are encoded in the genome. In general they involve the interaction of at least three gene products, specified by genes organized into an operon. Other families comprised 47 transport proteins similar to facilitators (and perhaps sometimes part of the ABC transport systems), 18 aminoacid permeases (probably antiporters), and at least 16 sugar transporters belonging to the PEP-dependent phosphotransferase system.

General stress proteins are important for the survival of bacteria under a variety of environmental conditions. We identified 43 temperature-shock and general stress proteins displaying strong similarity to E. coli counterparts.

Missing genes. Histone-like proteins such as HU and H-NS have been identified in E. coli. We found that B. subtilis encodes two putative histone-like proteins that show similarity to E. coli HU, namely HBsu and YonN, but found no homologue to H-NS. It is known that the $h b s$ gene encoding HBsu is essential, but we do not expect the yon $N$ gene to be essential because it is present in the SP $\beta$ prophage. IHF is similar to $\mathrm{HU}$, and it is not known whether HBsu plays a similar role to that of IHF in E. coli. Similarly, no protein similar to FIS could be found.

Genes encoding products that interact with methylated DNA, such as seqA in E. coli, involved in the regulation of replication initiation timing, or $m u t H$, the endonuclease recognizing the newly synthesized strand during mismatch repair at hemi-methylated

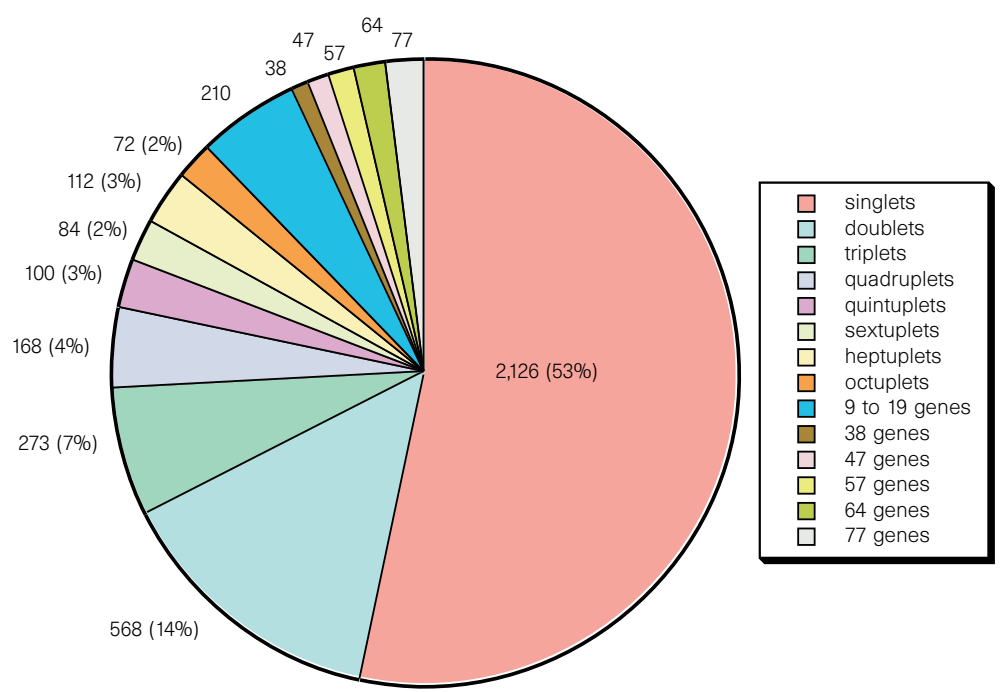

Figure 5 Gene paralogue distribution in the genome of $B$. subtilis. Each $B$. subtilis protein has been compared with all other proteins in the genome, using a Smith and Waterman algorithm. The baseline is established by making a similar comparison using 100 independent random shuffles of the protein sequence (Z-score > 13) 
GATC sites, are also missing. This is in line with the absence of known methylation in B. subtilis, equivalent to Dam methylation in E. coli. Similarly, E. coli sfiA, encoding an inhibitor of FtsZ action in the SOS response, has no counterpart in B. subtilis. In contrast, $B$. subtilis replication initiation-specific genes, such as $d n a B$ and $d n a D$, are missing in E. coli. The exact counterpart of the E. coli mukB gene, involved in chromosome partitioning, does not exist in B. subtilis, but genes spoOJ and $s m c$ (Smc is weakly similar to MukB), which are suggested to be involved in partitioning of the B. subtilis chromosome, are missing in E. coli.

Turnover of mRNA is controlled in E. coli by a 'degradosome' comprising RNase E. It has a counterpart in B. subtilis, but we failed to find a clear homologue of RNase E in this organism. Whether this is related to the role of ribosomal protein $\mathrm{S} 1$ as an RNA helicase involved in mRNA turnover in $E$. coli requires further investigation. In particular, a homologue of $r p s A$ (S1 structural gene), $y p f D$, might be involved in a structure homologous to the degradosome ${ }^{34}$.

Structurally unrelated genes of similar function. Several genes encode products that have similar functions in E. coli and B. subtilis, but have no evident common structure. This is the case for the helicase loader genes, E. coli dnaC and B. subtilis dnaI; the genes coding for the replication termination protein, E. coli tus and $B$. subtilis rtp; and the division topology specifier genes, E. coli minE and $B$. subtilis divIVA. The situation may even be more complex in multisubunit enzymes: $B$. subtilis synthesizes two DNA polymerase III $\alpha$ chains, one having $3^{\prime}-5^{\prime}$ proofreading exonuclease activity (PolC) and the other without the exonuclease activity (DnaE); in $E$. coli, only the latter exists. E. coli DNA polymerase II is structurally related to DNA polymerase $\alpha$ of eukaryotes, whereas B. subtilis YshC is related to DNA polymerase $\beta$.

\section{Metabolism of small molecules}

The type and range of metabolism used for the interconversion of low-molecular-weight compounds provide important clues to an organism's natural environment(s) and its biological activity. Here we briefly outline the main metabolic pathways of $B$. subtilis before the reconstruction of these pathways in silico, the correlation of genes with specific steps in the pathway, and ultimately the prediction of patterns of gene expression.

Intermediary metabolism. It has long been known that B. subtilis can use a variety of carbohydrates. As expected, it encodes an Embden-Meyerhof-Parnas glycolytic pathway, coupled to a functional tricarboxylic acid cycle. Further, B. subtilis is also able to grow anaerobically in the presence of nitrate as an electron acceptor. This metabolism is, at least in part, regulated by the FNR protein, binding to sites upstream of at least eight genes (four sites experimentally confirmed and four putative sites). A noteworthy feature of B. subtilis metabolism is an apparent requirement of branched short-chain carboxylic acids for lipid biosynthesis ${ }^{35}$. Branchedchain 2-keto acid decarboxylase activity exists and may be linked to a variety of genes, suggesting that $B$. subtilis can synthesize and utilize linear branched short-chain carboxylic acids and alcohols.

Amino-acid and nucleotide metabolism. Pyrimidine metabolism of $B$. subtilis seems to be regulated in a way fundamentally different from that of E. coli, as it has two carbamylphosphate synthetases (one specific for arginine synthesis, the other for pyrimidine). Additionally, the aspartate transcarbamylase of $B$. subtilis does not act as an allosteric regulator as it does in E. coli. As in other microorganisms, pyrimidine deoxyribonucleotides are synthesized from ribonucleoside diphosphates, not triphosphates. The cytidine diphosphate required for DNA synthesis is derived from either the salvage pathway of mRNA turnover or from the synthesis of phospholipids and components of the cell wall. This means that polynucleotide phosphorylase is of fundamental importance in nucleic acid metabolism, and may account for its important role in competence ${ }^{36}$. Two ribonucleoside reductases, both of class I, NrdEF type, are encoded by the B. subtilis chromosome, in one case from within the $\operatorname{SP} \beta$ genome. In this latter case, the gene corresponding to the large subunit both contains an intron and codes for an intein (V.L., unpublished data). The gene of the small subunit of this enzyme also contains an intron, encoding an endonuclease, as was found for the homologue in bacteriophage T4.

By similarity with genes from other organisms, there appears to be, in addition to genes involved in amino-acid degradation (such as the roc operon, which degrades arginine and related amino acids), a large number of genes involved in the degradation of molecules such as opines and related molecules, derived from plants. This is also in line with the fact that $B$. subtilis degrades polygalacturonate, and suggests that, in its biotope, it forms specific relations with plants.

Secondary metabolism. In addition to many genes coding for degradative enzymes, almost $4 \%$ of the $B$. subtilis genome codes for large multifunctional enzymes (for example, the srf, $p p s$ and $p k s$ loci), similar to those involved in the synthesis of antibiotics in other genera of Gram-positive bacteria such as Streptomyces. Natural isolates of $B$. subtilis produce compounds with antibiotic activity, such as surfactin, fengycin and difficidin, that can be related to the above-mentioned loci. This bacterium therefore provides a simple and genetically amenable model in which to study the synthesis of antibiotics and its regulation. These pathways are often organized in very long operons (for example, the $p k s$ region spans $78.5 \mathrm{~kb}$, about $2 \%$ of the genome). The corresponding sequences are mostly located near the terminus of replication, together with prophages and prophage-like sequences.

\section{Paralogues and orthologues}

It is important to relate intermediary metabolism to genome structure, function and evolution. We therefore compared the $B$. subtilis proteins with themselves, as well as with proteins from known complete genomes, using a consistent statistical method that allows the evaluation of unbiased probabilities of similarities between proteins ${ }^{37,38}$. For $Z$-scores higher than 13 , the number of proteins similar to each given protein does not vary, indicating that this cut-off value identifies sets of proteins that are significantly similar.

Families of paralogues. Many of the paralogues constitute large families of functionally related proteins, involved in the transport of compounds into and out of the cell, or involved in transcription regulation. Another part of the genome consists of gene doublets (568 genes), triplets (273 genes), quadruplets (168 genes) and quintuplets (100 genes). Finally, about half of the genome is made of genes coding for proteins with no apparent paralogues (Fig. 5). No large family comprises only proteins without any similarity to proteins of known function.

The process by which paralogues are generated is not well understood, but we might find clues by studying some of the duplications in the genome. Several approximate DNA repetitions, associated with very high levels of protein identity, were found, mainly within regions putatively or previously identified as prophages. This is in line with previous observations about PBSX and the skin element ${ }^{39,40}$, and suggests that these prophage-like elements share a common ancestor and have diverged relatively recently. In addition, several protein duplications are in genes that are located very close to each other, such as $y u k L$ and $d h b F$ (the corresponding proteins are $65 \%$ identical in an overlap of 580 amino acids), $y u g J$ and $y u g K$ (proteins $73 \%$ identical), $y x j G$ and $y x j H$ (proteins $70 \%$ identical), and the entire $o p u B$ operon, which is duplicated $3 \mathrm{~kb}$ away ( $о p u C$ operon, yielding $\sim 80 \%$ of amino-acid identity in the corresponding proteins).

The study of paralogues showed that, as in other genomes, a few classes of genes have been highly expanded. This argues against the idea of the genome evolving through a series of duplications of ancestral genomes, but rather for the idea of genes as living organisms, subject to evolutionary constraints, some being sub- 
mitted to expansion and natural selection, and others to local duplications of DNA regions.

Among paralogue doublets, some were unexpected, such as the three aminoacyl tRNA synthetases doublets (his $(2,817 \mathrm{~kb})$ and hisZ (3,588 kb); thrS (2,960 kb) and thrZ (3,855 kb); tyrS (3,036 kb) and $\operatorname{tyr} Z(3,945 \mathrm{~kb}))$ or the two mutS paralogues ( $m u t S$ and $y s h D)$. This latter situation is similar to that found in Synechocystis. In the case of B. subtilis, the presence of two MutS proteins could indicate that there are two different pathways for long-patch mismatch repair, possibly a consequence of the active genetic transformation mechanism of B. subtilis.

Families of orthologues. Because Mycoplasma spp. are thought to be derived from Gram-positive bacteria similar to B. subtilis, we compared the B. subtilis genome with that of M. genitalium. Among the 450 genes encoded by $M$. genitalium, the products of 300 are similar to proteins of $B$. subtilis. Among the 146 remaining gene products, a further 3 are similar to proteins of other Bacillus species, and 9 to proteins of other Gram-positive bacteria; 25 are similar to proteins of Gram-negative bacteria; and 19 are similar to proteins of other Mycoplasma spp. This leaves only 90 genes that would be specific to M. genitalium and might be involved in the interaction of this organism with its host.

The B. subtilis genome is similar in size to that of E. coli. Because these bacteria probably diverged more than one billion years ago, it is of evolutionary value to investigate their relative similarity. About 1,000 B. subtilis genes have clear orthologous counterparts in E. coli (one-quarter of the genome). These genes did not belong either to the prophage-like regions or to regions coding for secondary metabolism ( $\sim 15 \%$ of the B. subtilis genome). This indicates that a large fraction of these genomes shared similar functions. At first sight, however, it seems that little of the operon structure has been conserved. We nevertheless found that $\sim 100$ putative operons or parts of operons were conserved between E. coli and B. subtilis. Among these, $\sim 12$ exhibited a reshuffled gene order (typically, the arabinose operon is araABD in B. subtilis and araBAD in E. coli). In addition to the core of the translation and transcription machinery, we identified other classes of operons that were well conserved between the two organisms, including major integrated functions such as ATP synthesis (atp operon) and electron transfer (cta and qox operons). As well as being well preserved, the murein biosynthetic region was partly duplicated, allowing creation of part of the genes required for the sporulation division machinery ${ }^{41}$. The amino-acid biosynthesis genes differ more in their organization: the E. coli genes for arginine biosynthesis are spread throughout the chromosome, whereas the arginine biosynthesis genes of B. subtilis form an operon. The same is true for purine biosynthetic genes. Genes responsible for the biosynthesis of coenzymes and prosthetic groups in B. subtilis are often clustered in operons that differ from those found in E. coli. Finally, several operons conserved in E. coli and B. subtilis correspond to unknown functions, and should therefore be priority targets for the functional analysis of these model genomes.

Comparison with Synechocystis PCC6803 revealed about 800 orthologues. However, in this case the putative operon structure is extremely poorly conserved, apart from four of the ribosomal protein operons, the groES-groEL operon, $y f n H G$ (respectively in Synechocystis rfbFG), rpsB-tsf, ylxS-nusA-infB, asd-dapGA-ymfA, $\operatorname{spm} A B, \operatorname{efp}-a c c B, \operatorname{grp} E-d n a K, y u r X W$. The nine-gene atp operon of B. subtilis is split into two parts in Synechocystis: atpBE and atpIHGFDAC.

\section{Conclusion}

The biochemistry, physiology and molecular biology of B. subtilis have been extensively studied over the past 40 years. In particular, $B$. subtilis has been used to study postexponential phase phenomena such as sporulation and competence for DNA uptake. The genome sequences of $E$. coli and $B$. subtilis provide a means of studying the evolutionary divergence, one billion years ago, of eubacteria into the Gram-positive and Gram-negative groups. The availability of powerful genetic tools will allow the B. subtilis genome sequence data to be exploited fully within the framework of a systematic functional analysis program, undertaken by a consortium of 19 European and 7 Japanese laboratories coordinated by S. D. Ehrlich (INRA, Jouy-en-Josas, France) and by N. Ogasawara and H. Yoshikawa (Nara Institute of Science and Technology, Nara, Japan).

\section{Methods}

Genome cloning and sequencing. An international consortium was established to sequence the genome of B. subtilis strain 168 (refs 9, 10, 42). At its peak, 25 European, seven Japanese and one Korean laboratory participated in the program, together with two biotechnology companies. Five contiguous DNA regions totalling $0.94 \mathrm{Mb}$, and two additional regions of 0.28 and $0.14 \mathrm{Mb}$, were sequenced by the Japanese partners, while the European partners sequenced a total of $2.68 \mathrm{Mb}$. A few sequences from strain 168 published previously were not resequenced when long overlaps did not indicate differences.

A major technical difficulty was the inability to construct in E. coli gene banks representative of the entire $B$. subtilis chromosome using vectors that have proved efficient for other sources of bacterial DNA (such as bacteriophage or cosmid vectors). This was due to the generally very high level of expression of B. subtilis genes in E. coli, leading to toxic effects. This limitation was overcome by: cloning into a variety of vectors ${ }^{9,43,44}$; using an E. coli strain maintaining lowcopy number plasmids ${ }^{44}$; using an integrative plasmid/marker rescue genomewalking strategy ${ }^{44}$; and in vitro amplification using polymerase chain reaction (PCR) techniques ${ }^{45,46}$.

Although cloning vectors were used in the early stages as templates for sequencing reactions, they were largely superseded in the later stages by longrange and inverse PCR techniques. To reduce sequencing errors resulting from PCR amplification artefacts, at least eight amplification reactions were performed independently and subsequently pooled. The various sequencing groups were free to choose their own strategy, except that all DNA sequences had to be determined entirely on both strands.

Sequence annotation and verification. The sequences were annotated by the groups, and sent to a central depository at the Institut Pasteur ${ }^{14}$. The Japanese sequences were also sent there through the Japanese depository at the Nara Institute of Science and Technology. The same procedures were used to identify CDSs and to detect frameshifts. They were embedded within a cooperative computer environment dedicated to automatic sequence annotation and analysis $^{39}$. In a first step, we identified in all six possible frames the open reading frames (ORFs) that were at least 100 codons in length. In a second step, three independent methods were used: the first method used the GeneMark coding-sequence prediction method ${ }^{47}$ together with the search for CDSs preceded by typical translation initiation signals (5'-AAGGAGGTG-3'), located 4-13 bases upstream of the putative start codons (ATG, TTG or GTG); the second method used the results of a BLAST2X analysis performed on the entire $B$. subtilis genome against the non-redundant protein databank at the NCBI; and the third method was based on the distribution of non-overlapping trinucleotides or hexanucleotides in the three frames of an $\mathrm{ORF}^{48}$.

In general, frameshifts and missense mutations generating termination codons or eliminating start codons are relatively easy to detect. We shall devise a procedure for detecting another type of error, GC instead of CG or vice versa, which are much more difficult to identify. It should be noted that putative frameshift errors should not be corrected automatically. The sequences of the flanking regions of a 500-bp fragment centred around a putative error were sent to an independent verification group, which performed PCR amplifications using chromosomal DNA as template, and sequenced the corresponding DNA products.

Organization and accessibility of data. The B. subtilis sequence data have been combined with data from other sources (biochemical, physiological and genetic) in a specialized database, SubtiList ${ }^{49}$, available as a Macintosh or Windows stand-alone application (4th Dimension runtime) by anonymous FTP at $\mathrm{ftp} / / / \mathrm{ftp}$.pasteur.fr/pub/GenomeDB/SubtiList. SubtiList is also accessible through a World-Wide Web server at http://www.pasteur.fr/Bio/SubtiList.html, 
where it has been implemented on a UNIX system using the Sybase relational database management system. A completely rewritten version of SubtiList is in preparation to facilitate browsing of the information of the whole chromosome. Flat files of the whole DNA and protein sequences in EMBL and FASTA format will be made available at the above ftp address. Another B. subtilis genome database is also under development at the Human Genome Center of Tokyo University (http://www.genome.ad.jp), and SubtiList will also be available there.

Received 16 July; 29 September 1997.

Fleischmann, R. D. et al. Whole-genome random sequencing and assembly of Haemophilus influenza Rd. Science 269, 496-512 (1995).

2. Fraser, C. M. et al. The minimal gene complement of Mycoplasma genitalium. Science 270, 397-403 (1995).

3. Kaneko, T. et al. Sequence analysis of the genome of the unicellular Cyanobacterium Synechocystis sp. strain PCC6803. II. Sequence determination of the entire genome and assignment of potential protein-coding regions. DNA Res. 3, 109-136 (1996).

4. Bult, C. J. et al. Complete genome sequence of the methanogenic archaeon, Methanococcus jannaschii. Science 273, 1058-1073 (1996).

5. Himmelreich, R. et al. Complete sequence analysis of the genome of the bacterium Mycoplasma pneumoniae. Nucleic Acids Res. 24, 4420-4449 (1996).

6. Goffeau, A. et al. The yeast genome directory. Nature 387, 5-105 (1997).

7. Tomb, J.-F. et al. The complete genome sequence of the gastric pathogen Helicobacter pylori. Nature 388, 539-547 (1997).

8. Blattner, F. R. et al. The complete genome sequence of Escherichia coli K-12. Science 277, 1453-1462 (1997).

9. Kunst, F., Vassarotti, A. \& Danchin, A. Organization of the European Bacillus subtilis genome sequencing project. Microbiology 389, 84-87 (1995).

10. Ogasawara, N. \& Yoshikawa, H. The systematic sequencing of the Bacillus subtilis genome in Japan. Microbiology 142, 2993-2994 (1996).

11. Harwood, C. R. Bacillus subtilis and its relatives: molecular biological and industrial workhorses Trends Biotechnol. 10, 247-256 (1992).

12. Stragier, P. \& Losick, R. Molecular genetics of sporulation in Bacillus subtilis. Annu. Rev. Genet. 30, 297-341 (1996)

13. Solomon, J. M. \& Grossman, A. D. Who's competent and when: regulation of natural genetic competence in bacteria. Trends Genet. 12, 150-155 (1996).

14. Moszer, I., Kunst, F. \& Danchin, A. The European Bacillus subtilis genome sequencing project: current status and accessibility of the data from a new World Wide Web site. Microbiology 142, 2987-2991 (1996).

15. Franks, A. H., Griffiths, A. A. \& Wake, R. G. Identification and characterization of new DNA replication terminators in Bacillus subtilis. Mol. Microbiol. 17, 13-23 (1995).

16. Lobry, J. R. Asymmetric substitution patterns in the two DNA strands of bacteria. Mol. Biol. Evol. 13, 660-665 (1996)

17. Hénaut, A. \& Danchin, A. in Escherichia coli and Salmonella: Cellular and Molecular Biology (eds Neidhardt, F. et al.) 2047-2066 (ASM, Washington DC, 1996).

18. Nussinov, R. The universal dinucleotide asymmetry rules in DNA and amino acid codon choice Nucleic Acids Res. 17, 237-244 (1981).

19. Karlin, S., Burge, C. \& Campbell, A. M. Statistical analyses of counts and distributions of restriction sites in DNA sequences. Nucleic Acids Res. 20, 1363-1370 (1992).

20. Burge, C., Campbell, A. M. \& Karlin, S. Over- and under-representation of short oligonucleotides in DNA sequences. Proc. Natl Acad. Sci. USA 89, 1358-1362 (1992).

21. Kasahara, Y., Nakai, S. \& Ogasawara, H. Sequence analysis of the $36-\mathrm{kb}$ region between gnt $Z$ and $\operatorname{trn} Y$ genes of Bacillus subtilis genome. DNA Res. 4, 155-159 (1997).

22. Presecan, E. et al. The Bacillus subtilis genome from gerBC $\left(311^{\circ}\right)$ to licR $\left(334^{\circ}\right)$. Microbiology 143, 3313-3328 (1997)

23. Burkholder, P. R. \& Giles, N. H. Induced biochemical mutations in Bacillus subtilis. Am. J. Bot. 33 , 345-348 (1947)

24. Daniels, D. L., Plunkett, G. III, Burland, V. \& Blattner, F. R. Analysis of the Escherichia coli genome: DNA sequence of the region from 84.5 to 86.5 minutes. Science 257, 771-778 (1992).

25. Wu, L. J. \& Errington, J. Bacillus subtilis SpoIIIE protein required for DNA segregation during asymmetric cell division. Science 264, 572-575 (1994)

26. Itaya, M. Stability and asymmetric replication of the Bacillus subtilis 168 chromosome structure. J Bacteriol. 175, 741-749 (1993).
27. Billoud, B., Kontic, M. \& Viari, A. Palingol: a declarative programming language to describe nucleic acids' secondary structures and to scan sequence database. Nucleic Acids Res. 24, 1395-1403 (1996). 28. Fichant, G. A. \& Burks, C. Identifying potential tRNA genes in genomic DNA sequences. J. Mol. Biol. 220, 659-671 (1991).

29. d'Aubenton Carafa, Y., Brody, E. \& Thermes, C. Prediction of rho-independent Escherichia coli transcription terminators. A statistical analysis of their RNA stem-loop structures. J. Mol. Biol. 216, $835-858$ (1990).

30. Stock, J. B., Surette, M. G., Levitt, M. \& Park, P. in Two-Component Signal Transduction (eds Hoch, J. A. \& Silhavy, T. J.) 25-51 (ASM, Washington DC, 1995).

31. Mizuno, T. Compilation of all genes encoding two-component phosphotransfer signal transducers in the genome of Escherichia coli. DNA Res. 4, 161-168 (1997).

32. Perego, M., Glaser, P. \& Hoch, J. A. Aspartyl-phosphate phosphatases deactivate the response regulator components of the sporulation signal transduction system in Bacillus subtilis. Mol. Microbiol. 19, 1151-1157 (1996).

33. Tjalsma, H. et al. Bacillus subtilis contains four closely related type I signal peptidases with overlapping substrate specificities: constitutive and temporally controlled expression of different sip genes. J. Biol. Chem. 272, 25983-25992 (1997).

34. Danchin, A. Comparison between the Escherichia coli and Bacillus subtilis genomes suggests that a major function of polynucleotide phosphorylase is to synthesize CDP. DNA Res. 4, 9-18 (1997).

35. Suutari, M. \& Laakso, S. Unsaturated and branched chain-fatty acids in temperature adaptation of Bacillus subtilis and Bacillus megaterium. Biochim. Biophys. Acta 1126, 119-124 (1992).

36. Luttinger, A., Hahn, J. \& Dubnau, D. Polynucleotide phosphorylase is necessary for competence development in Bacillus subtilis. Mol. Microbiol. 19, 343-356 (1996).

37. Landès, C., Hénaut, A. \& Risler, J.-L. A comparison of several similarity indices used in the classification of protein sequences: a multivariate analysis. Nucleic Acids Res. 20, 3631-3637 (1992).

38. Glémet, E. \& Codani, J.-J. LASSAP, a LArge Scale Sequence compArison Package. Comput. Appl. Biosci. 13, 137-143 (1997).

39. Médigue, C., Moszer, I., Viari, A. \& Danchin, A. Analysis of a Bacillus subtilis genome fragment using a co-operative computer system prototype. Gene 165, GC37-GC51 (1995).

40. Krogh, S., O'Reilly, M., Nolan, N. \& Devine, K. M. The phage-like element PBSX and part of the skin element, which are resident at different locations on the Bacillus subtilis chromosome, are highly homologous. Microbiology 142, 2031-2040 (1996).

41. Daniel, R. A., Drake, S., Buchanan, C. E., Scholle, R. \& Errington, J. The Bacillus subtilis spoVD gene encodes a mother-cell-specific penicillin-binding protein required for spore morphogenesis. J. Mol. Biol. 235, 209-220 (1994).

42. Anagnostopoulos, C. \& Spizizen, J. Requirements for transformation in Bacillus subtilis. J. Bacteriol. 81, 741-746 (1961)

43. Azevedo, V. et al. An ordered collection of Bacillus subtilis DNA segments cloned in yeast artificial chromosomes. Proc. Natl Acad. Sci. USA 90, 6047-6051 (1993).

44. Glaser, P. et al. Bacillus subtilis genome project: cloning and sequencing of the $97 \mathrm{~kb}$ region from $325^{\circ}$ to $333^{\circ}$. Mol. Microbiol. 10, 371-384 (1993).

45. Ogasawara, N., Nakai, S. \& Yoshikawa, H. Systematic sequencing of the 180 kilobase region of the Bacillus subtilis chromosome containing the replication origin. DNA Res. 1, 1-14 (1994).

46. Sorokin, A. et al. A new approach using multiplex long accurate PCR and yeast artificial chromosomes for bacterial chromosome mapping and sequencing. Genome Res. 6, 448-453 (1996).

47. Borodovsky, M. \& McIninch, J. GENMARK: parallel gene recognition for both DNA strands. Comput Chem. 17, 123-133 (1993)

48. Fichant, G. A. \& Quentin, Y. A frameshift error detection algorithm for DNA sequencing projects. Nucleic Acids Res. 23, 2900-2908 (1995).

49. Moszer, I., Glaser, P. \& Danchin, A. SubtiList: a relational database for the Bacillus subtilis genome Microbiology 141, 261-268 (1995).

Acknowledgements. We thank C. Anagnostopoulos, R. Dedonder and J. Hoch for their pioneering efforts, and A. Bairoch for advice in annotating B. subtilis protein data. The main funding of the European network was provided by the European Commission under the Biotechnology program. The Japanese project was included in the Human Genome Program, and supported by a research grant from the Ministry of Education, Science and Culture, and the Proposal-Based Advanced Industrial Technology R\&D Program from New Energy and Industrial Technology Development Organization. The Swiss and Korean projects were funded by the Swiss National Fund and the Korean government, respectively. An some Europen biotechnology companies: DuPont de Nemours (France, USA), Frimond (Belgium), Genencor (Finland, USA), Gist Brocades (The Netherlands), Glaxo-Wellcome (UK, Italy), Hoechst Marion Roussel (France, Germany), F. Hoffmann-La Roche AG (Switzerland), Novo Nordisk (Denmark), SmithKline Beecham (UK).

Correspondence and requests for materials should be addressed to F.K. (e-mail: fkunst@pasteur.fr), N.O. (nogasawa@bs.aist-nara.ac.jp), H.Y. (hyoshika:bs.aist-nara.ac.jp) or A.D. (adanchin@pasteur.fr). The sequence has been deposited in $\mathrm{EMBL}$ GenBank/DDB] with accession numbers from Z99104 to Z99124.

\section{KNOW YOUR COPY RIGHTS} R E S P E C T

$T$ he publication you are reading is protected by copyright law.

Photocopying copyright material without permission is no different from stealing a magazine from a newsagent, only it doesn't seem like theft.
If you take photocopies from books, magazines and periodicals at work your employer should be licensed with CLA.

Make sure you are protected by a photocopying licence.
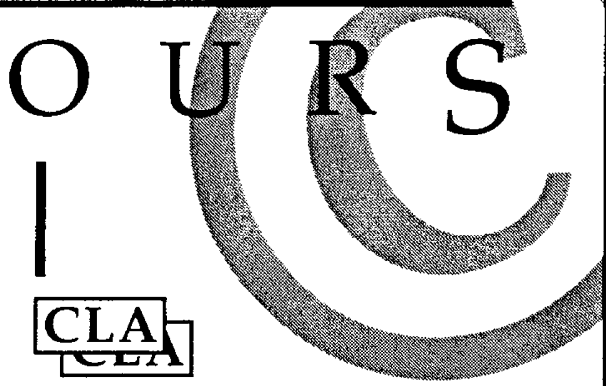

The Copyright Licensing Agency Limited 90 Tottenham Court Road, London W1P OLP Telephone: 01714365931 Fax: 01714363986 
Table 1. Functional classification of the Bacillus subtilisprotein-coding genes.

CELL ENVELOPEAND CELLULAR

11 CELLWAL

CW/A $2665 \mathrm{~N}$-acetylmuramoyl-L-alanine amidase (minor

CW/C 1873 autolysin)

No-acetylmuramoyy-L-alanine amidase (sporul
tion mother cell wall)

CWID 157 N-acetylmuramoyl-L-alanine amidase (germina-

WWIJ 282 cellwall hydrolase (sporulation)

dacA 18 penicillin-binding protein 5 (D-alanyl-D-alanine carboxypeptidase) (peptidoglycan biosynthe-

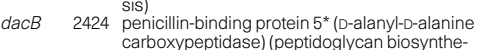

dacF 2445 sis) (sporececontex) penicilin-binding protein (D-alanyl-D-alanine car-

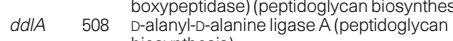

dltA 3951 D-alanyl-D-alanine carrier protein ligase (lipotei-

dlte 3955 involved in lipoteichoic acid biosynthes s

gcaD 56 UDP-N-acetylglucosamine pyrophosphorylase (peptidoglycan and lipopolysaccharide biosyn-

ggaA 3670 galactosamine-containing minor teichoic acid

ggaB 3669 galactosamin

gtaB 3665 UTP-glucose-1-phosphate uridylyttransferase

glatB 3662 modifier protein of major autolysin LytC

IytC 3660 (CWBP76)

3600 autolysin) (CWBPP49)

IytD $3687 N$ Nacetylglucosaminidase (major autolysin)

IytE 1018 cell wall lytic activity (CWBP33)

$\begin{array}{ll}\text { mblaY } & 3747 \text { MreB-llke protein } \\ \text { mraspho-N-acetylmuramoyl-pentapeptide }\end{array}$ transferase (peptidoglycan biosynthesis)

$\begin{array}{lll}m r e B & 2861 & \text { cell-shape determining protein } \\ \text { mreBH } & 1517 & \text { cell-shape determining protein }\end{array}$

$\begin{array}{lll}\text { mreBH } & 1517 & \text { cell-shape determining protein } \\ \text { mreC } & 2860 \text { cell-shape determining protein }\end{array}$

murA 3778 UDP-N-acetylglucosamine 1-carboxy vinyltrans-

murB 1592 Uerase (peptidoglycan biosynthesis)

murC 3049 Uase (peptidoglycan biosynthesis

murD 1588 G UDCan biosynthesis)

murE 1586 UDP-N-acetylmuramoylananine-D-gluta-

mate-2,6-diaminopimelate ligase (peptidoglycan biosynthesis)
UDP- $N$-acetylmuramoylalanyl-

UDP- $N$-acetylmuramoylalanyl-
D-glutamyl-2,6-diaminopimelate-D-alany

murG $\quad 1591$ DD-alanyll ligase (peptidoglycan biosynthesis) UDP-N-acetylglucosamine- $N$-acetylmuramyl-
(pentapeptide) pyrophosphoryl-undecaprenol
$N$-acetylglucososmine transferase (peptidogly-

murZ 3806 UDP-N-acetylglug

ferase (peptidoglycan biosynthesis)

pbp

pbpA 2583 penicililin-binding protein $2 A$ (peptidoglycan

pbpB 1581 penicililin-binding protein $2 \mathrm{~B}$ (peptidoglycan

pbpC $463 \quad \begin{aligned} & \text { biosynthesis) } \\ & \text { penicilin-binding protein } 3 \text { (peptidoglycan }\end{aligned}$

pbpD 3233 biosynthesis

pbpE $3535 \begin{aligned} & \text { biosynthesis) } \\ & \text { penicililin-binding protein } 4^{*} \text { (peptidoglycan }\end{aligned}$

pbpF 1083 penicillin-binding protein $1 \mathrm{~A}$ (peptidoglycan

pbpX $1765 \begin{aligned} & \text { biosynthesis) (germination) } \\ & \text { penicillin-binding protein (peptidoglycan biosyn- }\end{aligned}$

ponA 2341 penicililin-binding proteins $1 \mathrm{~A} / 1 \mathrm{~B}$ (peptidogly-

racE 2903 can biosynthesis) glutamate racemase (peptidoglycan biosynthe-

spoVD 1584 pensicillin-binding protein (peptidoglycan biosyn-

$\operatorname{tag} A 3680$ thesis) (spore cortex) involved in polyglycerol phosphate teichoic acid

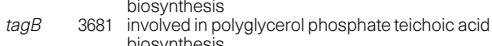

tagC 3682 involved in polyglycerol phosphate teichoic acid

tagD 3680 glycerol-3-phosphate cytidylyttransferase (tei-

tagE 3679 UDic-gadicoses:polyglyscerol phosphate glucosyl-

tagF $\quad 3677$ transferase (teichoic acid biosynthesis)

tagF 3677 CDP-glycerol:polyglycerol phosphate glycero-
phosphotransferase (teichoic acid biosynthephospho
sis)

tagG 3675 teichoic acid translocation (permease)

tagh 3674 teichoic acid translocation (ATP-binding protein)

3649 teichoic acid linkage unit synthesis
tuaA 3658 biosynthesis of teichuronic acid

tuaB 3657 biosynthesis of teichuronic acd

tuaC 3656 biosynthesis of teichuronic acid
tuad 3655 biosynthesis of teichuronic acid (UDP-glucose

6-dehydrogenase)

tuaF 3652 biosynthesis of teichuronic acid

uaG 3651 biosynthesis of teichuronic acid

tuaH 3650 biosynthesis of teichuronic acid

wapA 4029 cell wall-associated protein precursor

(C) 1153 (CWBP200, 105, 62

and serine protease CWBP52)
XlyB $\quad 1317 \begin{aligned} & \text { prophage-mediated lysis) } \\ & N \text {-acetylmuramoyl-Lalanine amidase (PBSX } \\ & \text { - }\end{aligned}$

yfnG 799 prophage-mediated lysis

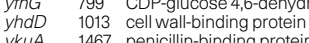

y|bl 1569 lipopolysaccharide core biosynthesis

ymaG 1865 cell wall protei

YngB 1946 UTP-glucose-1-phosphate uridylyltransferase

yocH 2093 cell wall-binding protein
yodJ 2135 D-alanyl-D-alanine carboxypeptidase

$\begin{array}{lll}\text { yojL } & 2116 & \text { cell wall-binding protein } \\ \text { yomC } & 2263 & N \text {-acetylmuramoyl--alanine amidase }\end{array}$

$\begin{array}{ll}\text { ypdQ } & 2310 \text { cell wall enzyme } \\ \text { yptP } & 2306 \text { cell wall synthesis } \\ \text { ypit } & 2357 \text { lipopolysaccharide biosynthesis-related protein }\end{array}$

yoeE $2649 \quad N$-acetylmuramoyl-Lalanine amidase

yafy 2588 peptidoglycan acetylation

anine amidase

$\begin{array}{ll}\text { yrhL } & 2771 \text { acyltransferase } \\ \text { yrrR } & 2791 \text { penicillin-binding protein }\end{array}$

ynt $2818 \mathrm{~N}$-acetylmuramoyl-L-alanine amidase

ytcC 3157 lipopolysaccharide $N$-acetylglucosaminytrans-

$y$ ttkC $\quad 3135$ autolytic amidase

ytxN 3161 lipopolysaccharide $N$-acetylglucosaminyttrans-

yubE $3191 \quad N$-acetylmuramoyl---alanine amidase

YWhE

ywtD 3697 murein hydrolase

1.2 TRANSPORT/BINDING PROTEINS AND

$\begin{array}{ll}\text { aapA } & \text { LPOPROTEINS } \\ 2766 \text { amino acid perme.......... } & \text { als }\end{array}$

alsT 1938 amino acid carrier protein

amyD 3098 sugartransport

appA 1213 oligopeptide ABC transporter (oligopeptide-

appB 1215 biligopeptide ABC transporter (permease

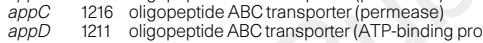

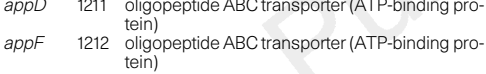

ein)
-arabinose transport (permease)

araN 2942 L-arabinose transport(sugar-binding protein)

arap

ara $Q$

azlC
azlD
$b g I P$$$
\begin{aligned}
& b / t \\
& b m \\
& b
\end{aligned}
$$

\section{cyd}

$C Z C D$

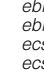
$2941 L$-arabinose transport (integral membrane protein) 2940 L-arabinose transport (integral membrane protein)
branched-chain amino acid transport 2728 branched-chain amino acid transport
4034 phosphotransferase system (PTS) $\beta$-glucosidephosphotransferase system (PTS) $\beta$-g
specific enzyme IIABC component 2716 multidrug-efflux transsoorter
2494 multidrug-efflux transporter

2494
3027
272 2728 branched-chain amino acid transporter
334 secondary transporter of the $\mathrm{Mg}^{2} /$ citrate comsecondary transporter of the
plex
$\alpha$-ketoglutarate permease

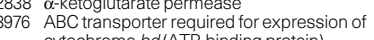

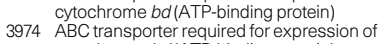
cytochrome bd (ATP-binding protein)
cation-efflux system membrane prote 2724 cation-efflux system membrane protein
1360 dipeptide ABC transporter (sporulation) ${ }_{1360}^{360}$ dipeptide ABC Cransporter (sporulation)
1361 dipeptide ABC transporter (permease) (sporulation)
162 dipeptide ABC transporter (permease) (sporula1363 titon)
dipeptide ABC transporter (ATP-binding protein) 1364 (sporulation) dipeptide ABC transporter (dipeptide-binding 364 dipeptide ABC transpon
protein) (sporulation)

1865 multidrug resistance protein

1864 multidrug resistance protein
1077 ABC transporter (ATP-binding protein)

1078 ABC transporter (membrane protein)

606 ATP-binding transport protein

183
182 iron-uptake system (binding protein)
iron-uptake system (integral membrane protein)

iron-uptake system (integral membrane protei

3415 ferrichrome ABC transporter (ATP-binding pro-

terin)
ferrichrome ABC transporter (ferrichrome-binding protein)

3416 ferrichrome ABC transporter (permease)

09 phosphotransferase system (PTS)
specific enzzyme llBC component

66 raminobutyrate permease

2802 glutamine ABC transporter (glutamine-binding) 2803 glutamine ABC transporter (membrane protein 2804 glutamine ABC transporter (membrane protein) 2802 glutamine ABC transporter (ATP-binding pro-

1002 gilycerol uptake facilitator

235 glycerol-3-phosphate permease
255
$\mathrm{H}^{+}$/glutamate symport protein

$1097 \mathrm{H}^{+} / \mathrm{Na}^{-}$-glutamamate symport prote

892 phosphotransferase system (PTS) arbutin-like enzyme liBC component 3004 histidinin transport protein (ATP-binding protein)
4046 histidine permease

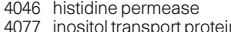

2322 2-keto-3-deoxygluconate permease (pectin uti330 lization)

2762 phosphotransferase system (PTS) fructose2762 specific enzyme IIA component

2761 specific enzyme llB component

作

$2760 \begin{aligned} & \text { specitic enzyme liC component } \\ & \text { phosphotransferase system (PTS) fructose- }\end{aligned}$

2700 phosphotransterase system (P)

3559 phosphotransferase system (PTS) lichenan
specific enzyme liA component

3961 specific enzyme IIA component phosphotransferase system (PTS) lichenan-

licC 3960 specific enzyme IIB component phosphtransferase system (PTS) lichenan-

specific enzyme IIC component

$\begin{array}{lll}\text { ImrB } & 290 & \text { specific enzyme liC component } \\ \text { IolA } & 779 & \text { lipooprotin-esistance protein }\end{array}$

$\begin{array}{llll}\text { IDIA } & 779 & \text { lipoprotein } \\ \text { IIIB } & 781 & \text { transmembrane lipoprotein } \\ \text { IDIC } & 782 & \text { transmembranelipoprotin }\end{array}$

$\begin{array}{lll}\text { lold } & 782 & \text { transmembrane lipoprotein } \\ \text { mdr } & 334 & \text { multidrug-efflux transporter (puromycin, ner- }\end{array}$ floxacin, tosufloxacin)

msmE 3097 multiple sugar-binding protein

msmX 3984 multiple sugar-binding transport ATP-binding

mt/A $449 \begin{aligned} & \text { protein } \\ & \text { phosphotransferase system (PTS) mannitol- }\end{aligned}$

nark 3833 nitrite extrusion protein

nasA 363 nitrate transponter

natA $296 \mathrm{Na}^{+} \mathrm{ABC}$ transporter (extrusion) (ATP-binding

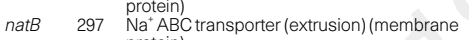

$\begin{array}{lll}\text { nrgA } & 3756 \text { ammonium transporter } \\ \text { nupC } & 4050 & \text { amrimidine-nuncoside }\end{array}$

nupC 4050 pyrimidine-nucleoside transport protein

(initiseptide ABC transporter (binding protein) (intitition of sporulation, competence develop-

oppB 1221 oligopeptide ABC transporter (permease) (initia-

OPDC 1222 tion of sporulation, competence development) tion of sporulation, competence development)
oppD $1223 \begin{aligned} & \text { oligopeptide ABC transporter (ATP-binding pro- } \\ & \text { tein) (initiation of sporulation, competence }\end{aligned}$ development) $\begin{array}{ll} & \text { devpF } 1224 \text { oligopopmentide ABC transporter (ATP-binding pro- } \\ \text { tein) (initiation of sporulation, competence }\end{array}$ tein) (intitition
development)

opuAA 321 devecine betaine ABC transporter (ATP-binding

opuAB 322 plyctine betaine $A B C$ transporter (permease)

OPUAC 323 (Osmoprotection)

betaine-binding protein) (osmor (glycine

opuBA 3462 choline ABC transporter (ATP-binding protein)

opuBB $3461 \begin{aligned} & \text { (osmoprotection) } \\ & \text { choline } A B C \text { transporter (membrane protein) }\end{aligned}$

opuBC 3460 (osmoprotection)

opUBC 3460 choline $\mathrm{ABC}$ transporter (choline-binding pro-
tein) (osmoprotection)

opuBD 3460 choline $A B C$ transporter (membrane protein)

opuCA $3470 \begin{aligned} & \text { (osmoprotection) } \\ & \text { glycine betaine/carnitine/choline ABC trans- }\end{aligned}$

opUCB $3469 \begin{aligned} & \text { porter (ATP-binding protein) (osmoprotection) } \\ & \text { glycine betaine/carnitine/choline ABC trans- }\end{aligned}$

opuCC 3468 porter (membrane protein)(osmoprotection)

opuCC 3468 glycine betaine/carntine/choline ABC Crans-
porter (osmoprotectant-binding protein) (osmo-

opuCD $3467 \begin{aligned} & \text { protection) } \\ & \text { glycine betaine/carnitine/choline ABC trans- }\end{aligned}$

opuD $3076 \begin{aligned} & \text { porter (membrane protein) (osmoprotection) } \\ & \text { glycine betaine transporter (osmoprotection) }\end{aligned}$

opuE 728 proline transporter (osmoprotection)

pbuX 2319 xanthine permease

-specific enzyme IABC component

ptsl 1459 phosphotransferase system (PTS) enzyme I

pyrP 1618 (general energy coupling protein of the PTS

rbsA 3703 ribose ABC transporter (ATP-binding protein)

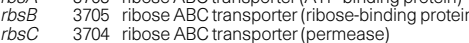

rbsD 3704 ribose ABC transporter (permease)

rocC 3876 amino acid permease (arginine and ornithine

rocE 4143 utilization)

utilization)

sacP 3904 phosphotransferase system (PTS) sucrose-

slp 1533 specific enzyme IIIC component

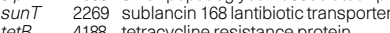

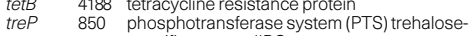

Specific enzyme lliBC component

$\begin{array}{lll}\text { trkA } & 2723 & \text { potassium uptake } \\ \text { yabM } & 65 & \text { amino acid transporter }\end{array}$

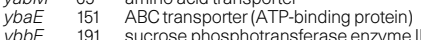

ybcL 191 sucrose phosphotransferase enzym

$\begin{array}{lll}y_{y b c L} & 212 & \text { chloramphenicol resistance protel } \\ y b d A & 217 & A B C \text { transporter (binding protein) }\end{array}$

ybdB 218 ABC transporter (permease)

$\begin{array}{lll}\text { ybeC } & 231 & \text { amino acid transporter } \\ \text { ybfS } & 257 \text { phosphotransferase system enzyme } \|\end{array}$

ybgF 262 histidine permease

ybgH 264 sodium/ proton-dependent alanine transporter 


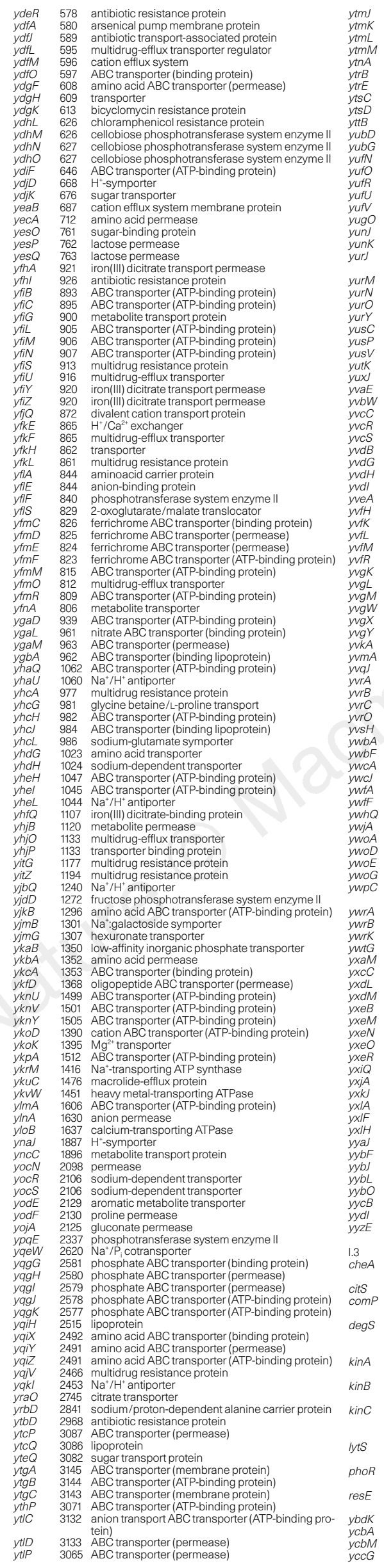

(

YTMM 3005 amino acid ABC transporter (permease)

$\begin{array}{lll}3125 & \text { proline permease } \\ 3118 & A B C \text { transporter (ATP-binding protein) }\end{array}$

ysC 3111 ABC transporter (ATP-binding protein)

3108 multidrug resistance paset

3192 multidrug resistance protein

$3188 \mathrm{Na}^{4}$-transporting ATP synthase

3239 ABC transporter (lipoprotein)

3244 organic acid transport protein

$3248 \mathrm{Na}^{+} / \mathrm{H}^{+}$antiporter
$3249 \mathrm{Na}^{+} / \mathrm{H}^{+}$antiporter

3218 potassium channel protein

3218 potassium channel

3345 multiple sugar ABC transporter (ATP-binding protein)

3348 sugar permease

3350 multiple sugar-binding protein

urY 3360 ABC transporter (ATP-binding protein)

3374 multidrug-efflux transporter
S

3379 iron(III) dicitrate transport permeas
$3307 \mathrm{Na}^{2}$ /nucleoside cotransporter

$3307 \mathrm{Na}^{\text {/ }}$ nucleoside cotransporter
3232 multidrug-efflux transporter

3232 multidrug-efllux transporter

3490 amino acid permease

3579 ABC transporter (ATP -binding protein)

$3565 \mathrm{ABC}$ transporter (permease)

3561 transporter

3555 maltose/maltodextrin-binding protein

3554 mattodextrin transport system permease

3510 L-lactate permeas

3508 maltose/maltodextrin-binding protein

3506 maltodextrin transport system permease

3505 maltodextrin transport system permease

3424 molybdenum-binding protein

324

3440 heavy metal-transporting ATPase

3443 heary metal-transporting ATPase

3443 mercuric transport protein

3618 multidrug-efflux transporter

3399 macrolide-efflux protein

3402 iron transport system

3403 iron-binding

3413 amino acid ABC transporter (ATP-binding protein)

3420 ABC transporter (amino acid permease)
3938 phosphotransferase system enzyme II

3933 sugar permease

$3923 \mathrm{Na}^{\mathrm{a}}$-dependent symport

3904 nitrite transporter

3837 ABC transpoorter (ATP-binding protein)

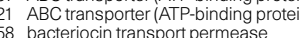

-5
5

(753 permease

749 antibiotic resistance protein
743 large conductance mechanosensitive channel large co
protein

721 chromate transport protein

3720 chromate transport protein
3712 arsenical pump membrane protein

3693 metabolite transport protein

4100 antibiotic resistance protein

40870 metabolite transport protein
4070 ABC transporter (ATP-binding protein)

4069 ABC transporter (permease)

$4066 \mathrm{ABC}$ transporter (binding protein)
4059 amino acid ABC transporter (binding protein)

4058 amino acid ABC transporter (permease)

4058 amino acid ABC transporter (ATP-binding protein)

4054 ethanolamine transporter
$4009 \mathrm{Mg}^{2} /$ citrate complex transporter

pyrrimidine nucleoside transport

3970 purine-cytosine permease

3968 ABC transporter (ATP-binding protein)

3966 multidrug-efflux transporter

4194 transporter

480 antibiotic resistance protein

4175 ABC transporter(ATP-binding protein)

$4169 \mathrm{ABC}$ transporter (permease)

$4159 \mathrm{ABC}$ transporter (permease)

4125 ABC transporter (ATP-binding protein)
4122 phosphotransferase systeme enzyme

SENSORS (SIGNAL TRANSDUCTION)

1712 two-component sensor histidine kinase
[CheB/CheY] chemotactic signal modulator

830 [CheB/CheY] chemotactic signal modulator

3255 two-component sensor histidine kinase [ComA] involved in early competence
3646 two-component sessoror histidine kinase [DegU]
involved in degradative enzyme and competence regulation
two-component sensor histidine kinase [Spoof]

1469 two-component sensor histidine kinase [SpOOF
involved in the initiation of sporulation

involved in the inititation of sporulation
3229 two-component sensor histidine kinase [SpoOF]

involved in the initiation of sporulation

two-component sensor histidine kinase [SpoOA]
involved in the initiation of sporulation (phosphoinvolved in the initial

relay-independent)
2957 two-component sensor histidine kinase [LytT]

involved in the rate of autolysis

2977 two-component sensor histidine kinase [PhoP]

involved in phosphate regulation
two-component sensor histidine kinase [ResD] involved in aerobic and anaerobic respiration

222 two-component sensor histidine kinase [Ybd]]

226 two-component sensor r histidine kinase [YcbB
279 two-component sensor histidine kinase $[Y c b \mid$

295 two-component sensor histidine kinase [YccH]
Nature $\odot$ Macmillan Publishers Ltd 1997 $\begin{array}{lll}\text { YClK } & 427 & \text { two-componentsensor histidine kinase [YClJ] } \\ \text { ydbF } & 497 & \text { two-componentsensor histidine kinase }[Y d b G\end{array}$

ydfH 587 two-component sensor histidine kinase $[Y d b G$

yesM 758 two-component sensor histidine kinase [Yes N]

\begin{tabular}{l} 
yfij \\
yhc 903 two-component sensor histidine kinase [Yrik] \\
\hline
\end{tabular}

yhil 1129 sensory transduction pleiotropic regulatory pro-

YKoH 1392 tein two-component sensor histidine kinase [YKoG]

YKRQ
YKVD
14192
two

yocF 2090 two-component sensor histidine kinase [YocG]
yrkQ 2704 two-componentsensor histidine kinase [YrkP]

ytrP 3035 two-componentsensor histidine kinase

ytsB
yufl
yuth
3236

YvCQ 3566 two-component sensor histidine kinase [YvcP

yvaB 3385 two-component sensor histidine kinase [YvaA

YVaE 3395 two-component sensor histidine kinase [YvaC]

yvrG 3407 two-componentsensor histidine kinase Y

YXCKK
Yot

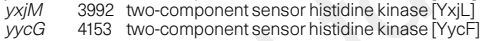

1.4 MEMBRANE BIOENERGETICS (ELECTRON

TRANSPORT CHAIN AND ATP

SYNTHAAE)................

$\begin{array}{ll}\text { atpA } & 3784 \text { ATP synthase (subunit of } \\ \text { atpB } & 3787 \text { ATP synthase (subunita }\end{array}$

atp C 3781 ATP synthase (subunit

3786 ATP synthase subunitit

atpF 3786 ATP synthase (subunitb)

atpG 3783 ATP synthase subunit

atpH 3775 ATP synthase subunitit

atpl 3787 ATP synthase (sub

cccA 2599 cytochrome $C_{550}$

CCdA 1922 required for a late step of cytochrome c synthesis

58 cytochrome caa ${ }_{3}$ oxidase (required for biosynths

559 cytochrome caa 0 oxidase (assembly factor)

ctaC 1560 cytochrome caa $a_{3}$ oxidase (subunit II)

ctaD 1561 cytochrome caa ${ }_{3}$ oxidase (subunit I)

ctaE 1563 cytochrome caa $a_{3}$ oxidase (subunit III)
ctaF 1563 cytochrome caa oxidase (subunit IV)

cydA 3978 cytochrome bd bubiquinol oxidase (subunit I)

ettA 2915 electron transfer flavoprotein ( $\alpha$ subunit)

ettB 2916 electron transfer flavoprotein ( $\beta$ subunit)

$\begin{array}{ll}\text { fer } & 2409 \text { ferredoxin } \\ \text { hmp } & 1372 \text { flavohemoglobin }\end{array}$

narG 3829 nitrate reductase ( $\alpha$ subun

nart 3825 niltate reduclase (\$ subunit)

narl 3823 nitrate reductase ( $\gamma$ subunit)

ndhF 205 NADH dehydrogenase (subunit5)

acrA 2364 menaquinol:cytochrome coxidoreductase (iron-

sulphur subunit

aCrB 2364 menaquinol:cytochrome coxidoreductase

gcrC 2363 (cytochrome bsubunit)

(cytochrome b/c subunit)

qox A

goxC 3914 cytochrome aa, quinol oxidase (subunit

qoxD 3913 cytochrome a a quinol oxidase (subunit IV)

resA 2421 essential protein similar to cytochrome $c$ biogene-

resB 2420 sis protein

sis protein protein similar to cytochrome c biogene

t/p 1930 thioredoxin-like protein

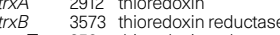

$\begin{array}{lll}y c g T & 352 & \text { thioredoxin reductase } \\ \text { ycnD } & 439 & \text { NADPH-flavin oxidoreductase }\end{array}$

$\begin{array}{lll}\text { yCnD } & 439 & \text { NADPH-flavin oxidoreductas } \\ y d b P & 508 & \text { thioredoxin }\end{array}$

ydeQ $\quad 598$ NAD(P)H oxidoreductase

ydgl 613 NADH dehydrogenase

$y+k O \quad 854 \mathrm{NAD}(\mathrm{P}) \mathrm{H}-\mathrm{flavin}$ oxidoreductase

818 quinone oxidoreductase
$\quad 1280$ cytochrome coxidase a

1290 cytochrome coxidase
yilD
yADHdehydrogenase

$\begin{array}{ll}\text { ykuN } & 1486 \text { flavedoxin } \\ \text { KkuP } & 1488 \text { sulfite reductase }\end{array}$

ykuU 1492 2-cys peroxiredox

$y k V N$
$y n e N$
1950

yoj 2114 nitric-oxide reductase

yol 2267 thioredoxin

ypdA 2401 thioredoxin reductase

yqiG $2516 \mathrm{NADH}$-dependentflavin oxidoreductase

$2475 \mathrm{NADH}$-dependent flavin oxidoreductase

yrkL $2708 \mathrm{NAD}(\mathrm{P}) \mathrm{H}$ oxidoreductase
ythA
3139 cytochrome doxidase subunt

3139 cytochrome d
3054 thioredoxin $\mathrm{H} 1$

3117 cytochrome coxidase subun

3116 cylochrome coxidase subunit

3249 NADH dehydrogenase (ubiquinone)

$\begin{array}{lll} & 3246 & \mathrm{NADH} \text { dehydrogenase } \\ \text { yumB } & 3300 \mathrm{NADH} \text { dehydrogenase }\end{array}$

yumC

$\begin{array}{ll}\text { yusE } & 3364 \text { thioredoxin } \\ \text { yut } & 3308 \text { NADH dehydrogenase }\end{array}$

WvaB $3445 \mathrm{NAD}(\mathrm{P}) \mathrm{H}$ dehydrogenase (quinone)

WWCG 3911 NADPH-flavin oxidoreductase
WWhN 3840 ubiquinol-cytochrome creductase

ywhN 3840 ubiquinol-cytochrome cred
ywro $3708 \mathrm{NAD}(\mathrm{P}) \mathrm{H}$ oxidoreductase

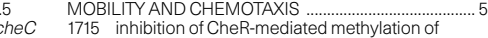

methyl-accepting chemotaxis proteins

cheD 1715 required for methylation of methyl-accepting

cheR 2380 chethytaxis proteins by CheR metepting chemotaxis proteins methyl-

cheV 1473 modulation of Che A activity in response to attracthe
tants (CheW and CheY Similar domains) tants

$\begin{array}{ll}\text { flgB } & 1691 \text { flagellar basal-body rod protein } \\ \text { flgC } & 1691 \text { flagellar basal-body rod protein }\end{array}$ 


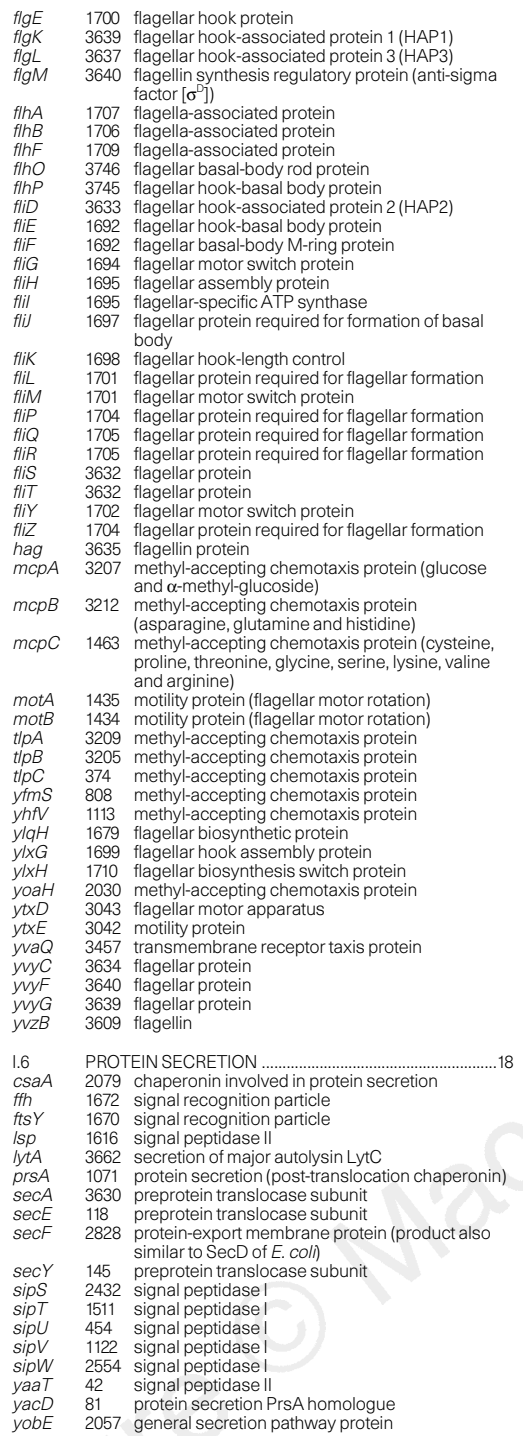

$\begin{array}{ll}1.7 & \text { CELL DIVISION ............................................. } \\ 1593 \text { cell-division initition protein (septum formation) }\end{array}$

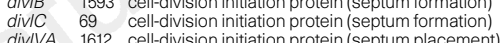
$\begin{array}{lll}\text { divIVA } & 1612 \text { cell-division initiation protein (septum plac } \\ \text { ftsA } & 1596 \text { cell-division protein (septum formation) }\end{array}$

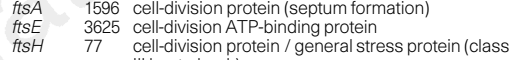

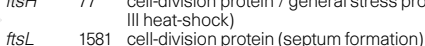

$\begin{array}{ll}\text { ItSL } & 1581 \text { cell-division protein (septum formation) } \\ \text { ftsX } & 3624 \text { cell-division protein } \\ \text { fsSZ } & 1597 \text { cell-division initiation protein (septum formation) }\end{array}$

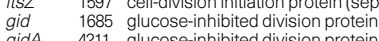

gidA 4211 glucose-inhibited division protein

$\begin{array}{ll}\text { gidB } & 4209 \text { glucose-inhibited division protein } \\ \text { maf } & 2862 \text { septum formation } \\ \text { minC } & 2859 \text { cell-divisioninhibitor (sentum placement }\end{array}$

mind 2858 cell-division inhibitor (septum placement)

(ATPase activator of MinC)
(ell-cycle protein

$\begin{array}{lll}\text { yacA } & 75 & \text { cell-cycle protein } \\ \text { yhth } & 925 & \text { cell-division inhibitor }\end{array}$

yjoB 1314 cell-division protein FtsH homologue

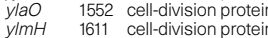

ywcF 3912 cell-division protein

1.8 SPORULATION ...................................................... 139

$\begin{array}{ll}\text { bofA } & 30 \text { inhibitor of the pro- } \sigma \text { processing machin } \\ \text { bofC } & 2837 \text { forespore regulator of the } \sigma^{\alpha} \text { checkpoint }\end{array}$

cgeA 2148 maturation of the outermost layer of the spore
cgeB 2148 maturation of the outermost layer of the spore

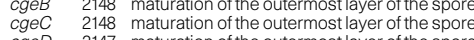

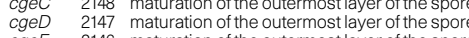

cgeE 2146 maturation of the outermost layer of the spore

$\begin{array}{lll}\cot A & 685 & \text { spore coat protein (outer) } \\ \cot B & 3715 \text { spore coat protein (outer) }\end{array}$

cotC 1905 spore coat protein (oute)

cotD 2332 spore coat protein (inner)
cote
1774 spore coat protein (outer)

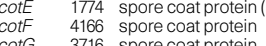

$\begin{array}{ll}\text { cotG } & 3716 \text { spore coat protein } \\ \text { cotH } & 3716 \text { spore coat protein (inner) }\end{array}$

$\begin{array}{lll} \\ \operatorname{coth} H & 3716 & \text { spore coat protein (inner) } \\ \cot A & 755 & \text { polypeptide composition of the spore coa }\end{array}$

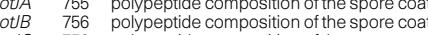

cotC 756 polypeptide composition of the spore coa

cotK 1926 spore coat protein

$\begin{array}{lll}\text { cott } & 1926 & \text { spore coat protein } \\ \text { cotM } & 1925 & \text { spore coat protein (outer) }\end{array}$

$\begin{array}{ll}1925 & \text { sore coat protein (outer) } \\ \text { cotN } & 2553 \\ \text { spsore coat-associated protein }\end{array}$

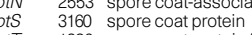

1280 spore coat protein (inner)

1251 spore coat protein (insoluble fraction)
1251 spore coat protein (insoluble fraction)

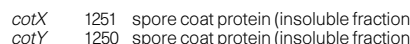

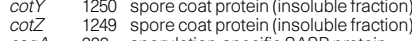

csgA 228 sporulation-specific SASP protein

$\begin{array}{lll}\text { jag } & 4213 \text { Spollly-associated protein } \\ \text { KaoB } & 3230 \text { activator of KinB in the initiation of sporulation }\end{array}$

KapD 3232 inhibitor of the KinA pathway to sporulation

kbaA 159 activation of the KinB signaling pathway to sporu-

obg 2853 GTP-binding protein involved in initiation of sporu-

phrA 1316 phosphatase (RapA) inhibitor (imported by Opp)

$\begin{array}{ll} & \text { phosphatase (RapC) regulator / Compdo } \\ \text { sporulation stimulating factor (CSF) }\end{array}$

phrE $\quad 2660$ phosphatase (RapE) regulator
phrF
3846 phosphatase (RapF) regulator

PhrF
3846 phosphatase (RapF) regulator
phrG
4141 phosphatase (RapG) regulator

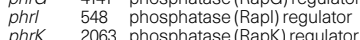

rapA 1315 response regulator aspartate phosphatase

rapB 3771 [esponsse regulator aspartate phosphatase

rapC 428 response regulator aspartate phosphatase

rapD 3743 response regulator aspartate phosphatase

rapF 3845 response regulator aspartate phosphatase

rapG 4139 response regulator aspartate phosphatase

$\mathrm{rapH} \quad 750$ response regulator aspartate phosphatase

$\begin{array}{lll}\text { rapl } & 547 & \text { response regulator aspartate phosphatase } \\ \text { rapj } & 304 & \text { response regulator aspartate phosphatase }\end{array}$

rapj 304 response regulator aspartate phosphatase
rapK 2061 response regulator aspartate phosphatase

rapk 2061 response regulator aspartate phosphatase
sinl 2552 antagonist of SinR

$\begin{array}{ll}\text { Sinl } & 2552 \text { antagonist to } \operatorname{SinR} \\ \text { soj } & 4206 \text { centromere-like function involved in forespore }\end{array}$ chromosome partitioning / inhibition of SpoOA

splB 1461 activation spore photoproduct lyas

spmA 2423 spore maturation protein (spore core dehydrata$\begin{array}{lll}\text { spmB } 2422 \text { tion) } & \text { spore maturation protein (spore core dehydrata- }\end{array}$ SpoOB 2854 tion)
sporulation initiation phosphoprotein (part of
phosh

SPOOE 1430 negative sporulation regulatory phosphatase

spoos 4206 chromosome positioning near the pole and tran spoll/AA 2444 port through the polar septum / antagonist of So

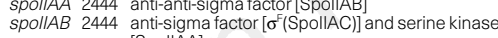
spollB 2864 [SpolliA] spollD $3777 \begin{aligned} & \text { mutation) } \\ & \text { required for complete dissolution of the asymmet }\end{aligned}$ spollE 71 ric serine phosphatase [SpollAA P P] ( $\sigma^{E}$ activation) spolin spoll/GA 1603 protease (processing of pro- $\sigma^{E}$ to active $\sigma^{E}$ ) SpollIIAB 2536 mutants block sporulation atter engulfmen spollliAC 2535 mutants block sporulation after engulfment spolll/AD 2555 mutants block sporulatition atter engulfment Spoll/AE 2535 mutants block sporulation after engulfment
SpollIAF 2534 mutants block sporulation after engulfment SpolllAF 2534 mutants block sporulation after engulfment
SpollIAG 2533 mutants block sporulation after engulfment Spolll $A G 2533$ mutants block sporulation after engulfment
spollIA 2532 mutants block sporulation after engulfment SPoIIIAH 2532 mutants block sporulation after engulfment
spollIE 1752 DNA translocase required for chromosome part-
tioning through the septum into the forespore spollII 4214 essential for $\sigma^{6}$ activity at stage III SpolIM 2450 required for dissolution of the septal cell wall SpollP 2634 required for dissolution of the septal cell wall SpollQ 3760 required for completion of engulfment

SpollR 3794 required for processing of pro- $\sigma^{2}$
SpolliSA 1349 lethal when synthesized during vegetative growth

spollSB 1348 in the absention blocks sporulation after septum form spolvA 2387 required for proper spore cortex formation and spolvB $2520 \begin{aligned} & \text { coat assembly } \\ & \text { intercompartmental signalling of pro- } \sigma^{k} \text { process- }\end{aligned}$ spoIVCA 2654 ing/activation in the mother-cell site-specific DNA recombinase required for creatspolvFA 2857 ing the sigk gene (excisision of the skin element)

SpoIVFB 2856 protease (processing of pro- $\sigma^{k}$ to active $\sigma^{k}$ )
SpoVAA 2443 mutants lead to the production of immature SpoVAB 2442 spores mutants lead to the production of immature spoVAC 2441 spores mutants lead to the production of immature SpoVAD $2441 \begin{gathered}\text { spores } \\ \text { mutants lead to the production of immature }\end{gathered}$ SPOVAE 2440 spores mutants lead to the production of immature SpoVAF 2439 mutants lead to the production of immature spoVB 2829 involved in spore cortex synthesis spoVC 60 thermosensitive mutant blocks spore coat forma spoVE 1590 tion required for spore cortex synthesis SpOVFA 1744 dipicolinate synthase subunit $A$

spoVG 56 required for spore cortex synthes

spoVID 2872 required for assembly of the spore coat spovk 1873 disruption leads to the production of immature
spores spoVM 1655 required for normal spore cortex and coat synthespoVR 1015 sis involved in spore cortex synthesis

spovS 1769 required for dehydratation of the spore core and

SpSA 3892 spore coat polysaccharide synthesis

SPSB 3891 spore coat polysaccharide synthes

SPSC
SOSD
38899

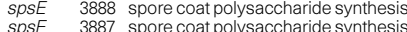

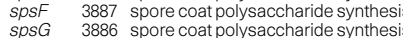

spsI 3885 spore coat polysaccharide synthes

SPSJ 3884 spore coat polysaccharide synthesis

SSPA 3025 small acid-soluble spore protein (major $\alpha$-type

sspB 1050 SASPll acid-soluble spore protein (major $\beta$-type

$\begin{array}{lll}\text { SSPC } & 2155 & \text { SASP) } \\ \text { SAall acid-soluble spore protein (minor } \alpha / \beta \text {-type }\end{array}$

1413 small acid-soluble spore protein (minor $\alpha / \beta$-type
Nature $\odot$ Macmillan Publishers Ltd 1997
SSpE $\quad 937 \begin{aligned} & \text { SASP) } \\ & \text { Small acid-soluble spore protein (major } \gamma \text {-type } \\ & \text { SASP) }\end{aligned}$

sspF $53 \begin{aligned} & \text { small acid-soluble spore protein (minor } \alpha / \beta \text {-type } \\ & \text { SASP) }\end{aligned}$

usd 3748 required for translation of spolliD

$y k n T \quad 1495$ sporulation protein $\sigma^{E}$-controlled

ynzH 1901 spore cortex membrane protein
spore coat protein

yobW 2083 membrane protein $\sigma^{k}$-controlled

yagT $2568 \gamma$-D-glutamyl-L-diamino acid endopeptidase I

$\begin{array}{ll}\text { yqjG } & 2483 \text { lipoprotein SpolllI-like } \\ \text { yraD } & 2754 \text { spore coatprotein }\end{array}$

yraE 2754 spore coat protein

yraF 2752 spore coat protein

yraG 2752 spore coat protein

yrbB 2844 spore coat protein

yrbC $\quad 2843$ sporecoat protein

ytaA 3161 spore coat protein

$\begin{array}{lll}\text { ytgP } & 3074 & \text { spore cortex protein } \\ \text { ytp } & 3051 \text { DNA translocase stage III sporulation protein }\end{array}$

yyaA 4208 DNA-binding protein Spo0J-like

$\begin{array}{ll}1.9 & \text { GERMINATION } \\ \text { gerAA } & 3390 \text { germina............................ } \\ \text { gera } & 391\end{array}$

$\begin{array}{llll}\text { gerAA } & 3390 & \text { germination response to L-alanine } \\ \text { gerAB } & 3391 & \text { germination response to L-alanine }\end{array}$

gerAC 3392 germination response to L-alanine
gerBA 3688 germination response to the combination of glu-

cose, fructose, L-asparagine, and KCl
gerBB 3689 germination response to the combination of glu-

gerBC 3690 germination response to the combination of glu-

gerCA 2384 cose, fructose, $\mathrm{L}$-asparagine, and $\mathrm{KCl}$

(menaquinone biosynthesis)

gerCB 2383 menaquinone biosynthesis methyltransferase

gerCC (menaquinone biosynthesis)

2382 heptaprenyl diphosphate synthase component II

gerD 159 (menaquinone biosynthesis)

combination of glucose, fructose, $L$-asparagine

gerKA 420 germination response to the combination of glu-

gerKB 423 cose, fructose, L-asparagine, and $\mathrm{KCl}$ germination response to the combination of glu-

gerKC 421 germination response to the combination of glu-

gerM 2902 germination (cortex hydrolysis) and sporulation

gpr 2635 spore protease (degradation of SASPs)

sleB 2399 spore cortex-lytic enzyme

yfkQ 850 spore germination respons

yfkR 848 spore germination protein

YKVT 1448 spore germination proten

yndD 1907 spore cortex-lytic enzyme

yndE 1908 spore germination protein

1.10 TRANSFORMATION/COMPETENCE ...........................20

cinA 1763 competence-damage inducible proten

comC 2864 late competence protein required for processing

and translocation of ComGC

COMEB 2640 late competence

comEC 2639 late competence operon required for DNA bind-

COMER 2640 ing and uptake

COMFA 3643 late competence protein required for DNA uptake

COMFB 3641 late competence gene

comGA 2559 late competence gene

comGB 2558 DNA transport machinery

comGC 2557 exogenousDNA-binding

comGD 2557 DNA transportmachinery

comGE 2557 DNA transport machinery

comGF 2556 DNA transport machine

coms 390 assembly link between regulatory components of

comX 3255 competence pheromone precursor (activation of

ComA)

$\begin{array}{lll}\text { mecA } & 1229 & \text { negative regulator of competence } \\ \text { ypbH } & 2403 \text { negative regulation of competence MecA homo- }\end{array}$

$\| \quad$ INTERMEDIARY METABOLISM 742

II.1 METABOLISM OF CARBOHYDRATES AND RELATED

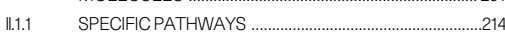

$\begin{array}{ll}\text { abfA } & 2939 \alpha \text {-L-arabinofuranosidase } \\ a b n A & 2949 \text { arabinan-endo 1,5--L-arabinase (degradation of }\end{array}$

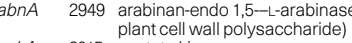

ackA 3015 acetate kinase

dependent $\alpha$ subunit)

880 acetoin dehydrogenase E1 component(TPP-

acoC 881 acetoin dehydrogenase E2 component (dihy

acol 882 drolipoamide acetyltransferase)

acoL 882 acetoin dehydrogenase E3 component (dihy-

acsA 3039 acetyl-CoA synthetase

acuA 3039 acetinutilization

acuB $\quad 3040$ acetoin utilization

adhA 2756 NADP-dependent alcohol dehydrogenas

adhB 2753 alcohol dehydrogenase

ald $\quad$ ald $\quad 4093$ aldehyde dehydrogenase

alsD $3709 \alpha$-acetolactate decarboxylase (acetoin biosynthe-

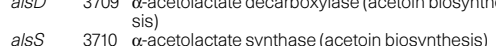

amyE $327 \quad \alpha$-amylase

amyX 3063 pullulanase

araA 2948 L-arabinose isomerase (L-arabinose utilization)

$\begin{array}{lll}\operatorname{araB} & 2946 & \text { L-ribulokinase (L-arabinose utilization) } \\ \operatorname{araD} & 2945 & \text { L-ribulose-5-phosphate 4-epimerase (L-arabinose }\end{array}$

utilization)

araL 2944 L-arabinose operon

araM 2943 L-arabinose operon

$\begin{array}{lll}\text { bglA } & 4122 & 6 \text {-phospho--glucosidase } \\ \text { bglC } & 1940 & \text { endo-1,4-glucanase (cellulose degradation) }\end{array}$ 


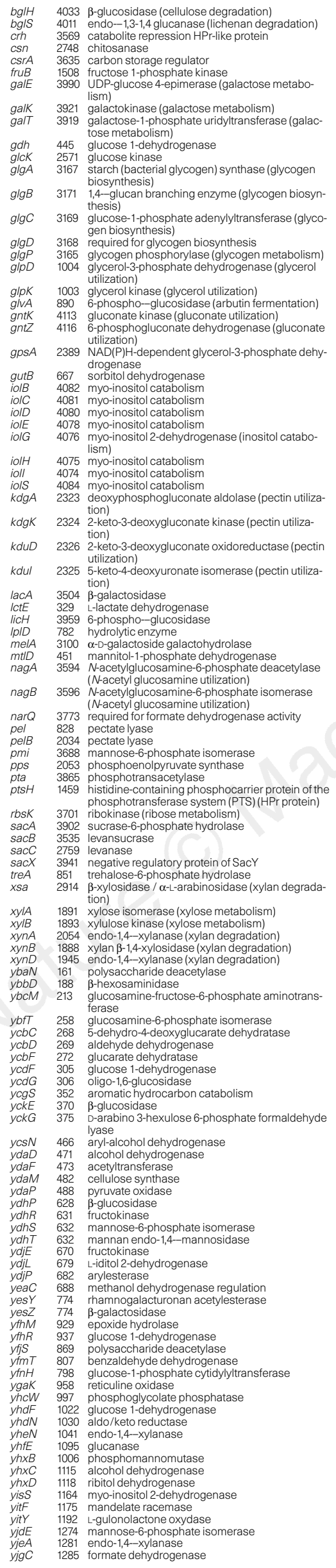

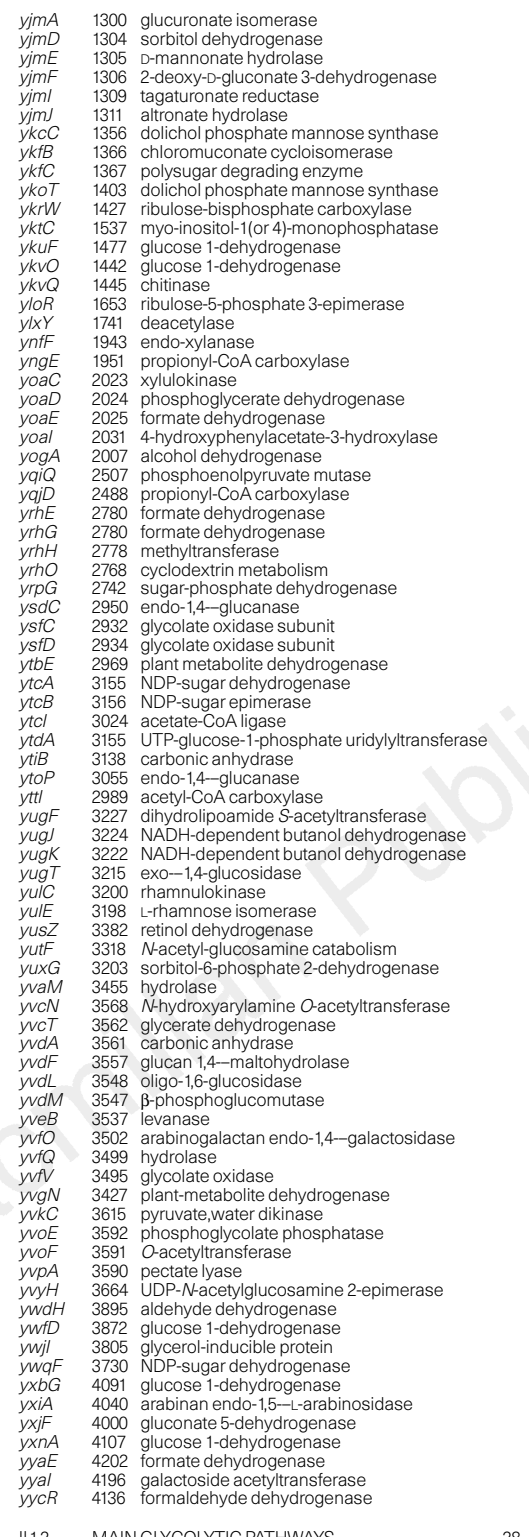

II.12 MAIN GLYCOLYTIC PATHWAYS ..................................28

eno 3477 enolase (glycolysis)

$\begin{array}{lll}f b a A & 3808 & \text { fructose-1,6-bisphosphate aldolase (glycolysis) } \\ f b p & 4127 \text { fructose-1,6-bisphosphatase (gluconeogenesis) }\end{array}$

$\begin{array}{lll}\text { fbp } & 4127 & \text { fructose-1,6-bisphosphatase (gluconeogenesis) } \\ \text { gap } & 3482 \text { glyceraldehyde } 3 \text {-phosphate dehydrogenase (gly- }\end{array}$

gapB $2967 \begin{aligned} & \text { colysis) } \\ & \text { glyceraldehyde 3-phosphate dehydrogenase (gly- }\end{aligned}$

ioll 4073 fructose-1,6-bisphosphate aldolase (glycolysis)

pckA 3129 phosphoenolpyruvate carboxykinase

d dhA 1529 pyruvateder

pdhC 1530 pyruvate dehydrogenase (dihydrolipoamide

1530 acetyltransferase E2 subunit)

1531 pyruvate dehydrogenase / 2-oxoglutarate dehydrogenase (dihydrolipoamide dehydrogenase E3

pfk $\quad 2987$ 6-phosphofructokinase (glycolysis)

pgi 3221 glucose-6-phosphate isomerase (glycolysis)

pgm 3478 phosphoglycerate mutase (glycolysis)

pycA 1554 pyruvate carboxylase
pykA 2986 pyruvate kinase (glycolysis)

$\begin{array}{ll}\text { pykA } & 2986 \text { pyruvate kinase (glycolysis) } \\ \text { tkt } & 1919 \text { transketolase (pentose phosph }\end{array}$

1919 transketolase (pentose phosphate)
tpi 3479 triose phosphate isomerase (glycolysis)

bbT 198 phosphoglucomutase (glycolysis)

558 glyceraldehyde 3-phosphate dehydrogenase (gly- hisH

1109 phosphoglycerate mutase (glycolysis)

yeC 2651 6-phosphogluconate dehydrogenase (pentose

2501 phosphate)

yajl 2481 6-phosphogluconate dehydrogenase (pentose

phosphate)
2478 glucose-6-phosphate 1-dehydrogenase (pentose

phosphate)
3807

ywjH 3807 transaldolase (pentose phosphate)
ywIF $\quad 3791 \begin{aligned} & \text { ribose } 5 \text {-phosphate epimerase (pentose phos- } \\ & \text { phate) }\end{aligned}$

Il.1.3
citA
citB
citC
citG
citt
citz
mals

1021 citrate synthase I

2980 isocitrate dehydrogenase

3389 fumarate hydratase

2979 malate dehydroge $m m g D \quad 2510$ citrate synthase III

(E1 subunit)

2108 2-oxoglutarate dehydrogenase (dihydrolipoamide

SdhA 2907 transsuccinylase, E2 subunit)

sdhB 2905 succinate dehydrogenase (iron-sulphur protein)
sdhC 2908 succinate dehydrogenase (cytochrome $b_{558}$ sub-

sdhC 2908 succin

sucC 1680 succinyl-CoA synthetase ( $\beta$ subunit)

mehydrogenase

2452 malate dehydrogenase

ywkA 3801 malate dehydrogenase

II.2 METABOLISM OFAMINO ACIDS AND RELATED

ald $\quad 3277$ L-alanine dehydro................

ISA

$\begin{array}{lll}\text { aprE } & 1105 & \text { L-aspartase } \\ \text { extracellular alkaline serine protease (subtilisin } E \text { ) }\end{array}$

aprX 1862 intracellular alkaline serine protease

argB $1197 \mathrm{~N}$-acetylglutamate 5-phosphotransferase (argi-

$\arg C \quad 1195 \quad N$-acetylglutamate $\gamma$-semialdehyde dehydroge-

argD 1198 N-acetylonithinesynthesis)

$\arg E \quad 2142$ acetylornithine deacetylase (arginine biosynthe-

argF $1203 \begin{aligned} & \text { sis) } \\ & \text { ornithine carbamoyltransferase (arginine biosyn- }\end{aligned}$

$\arg G \quad 3013 \begin{aligned} & \text { thesis) } \\ & \text { argininosuccinate synthase (arginine biosynthe- }\end{aligned}$

$\operatorname{argG} \quad 3013$ argin)

argH $\quad 3012$ argininosuccinate lyase (arginine biosynthesis)

1196 ornithine acetyltransferase / amino-acid acetyl-

aroA $3046 \begin{aligned} & \text { transferase (arginine biosynthesis) } \\ & 3 \text {-deoxy-D-arabino-heptulosonate 7-phosphate }\end{aligned}$ synthase / chorismate mutase-isozyme 3 (shiki-

aroB $\quad 2378$ 3-dehydroquinate synthase (shikimate pathway)

$\begin{array}{lll} & \text { way) } \\ \text { aroD } & 2645 \text { shikimate 5-dehydrogenase (shikimate pathway) } \\ \text { aroE } & 2368 \text { 5-enolpyruvoylshikimate-3-phosphate synthase }\end{array}$

$\begin{array}{lll}\text { aroE } \quad 2368 & \begin{array}{l}5 \text {-enolpyruvoylshikimate-3-phosphate sy } \\ \text { (shikimate pathway) }\end{array} \\ & \end{array}$

$\begin{array}{ll}\text { aroF } & 2380 \text { chorismate synthase (shikimate pathway) } \\ \text { aroH } & 2377 \text { chorismate mutase (isozymes } 1 \text { and 2) (aromatic }\end{array}$

$2377 \begin{gathered}\text { chorismate mutase (isozymes } 1 \text { and } 2 \text { (arids } \\ \text { amino acids biosynthesis) }\end{gathered}$
shikimate kinase (shikimate pathway)

asd 1745 aspartate-semialdehyde dehydrogenase

ask 2910 aspartokinase II attenuator

asnB 3127 asparagine synthetase

$\begin{array}{lll}\text { asnH } & 4098 \text { asparagine synthetase } \\ \text { aspB } & 2348 \text { aspartate aminotransferase }\end{array}$

$\begin{array}{lll}\text { aspB } & 2348 \text { aspartate aminotransferase } \\ \text { bCSA } & 2317 \text { naringenin-chalcone synthase (phenylalanine }\end{array}$

$\begin{array}{lll}2317 & \begin{array}{l}\text { naringenin-chalcone synthase (phenylalanine } \\ \text { metabolism) }\end{array}\end{array}$

bfmBAA 2499 branched-chain $\alpha$-keto acid dehydrogenase E1

bfmBAB 2498 (2-oxoisovalerate dehydrogenase $\alpha$ subunit)

(2-oxoisovalerate dehydrogenase $\beta$ subunit)

bfmBB 2497 branched-chain $\alpha$-keto acid dehydrogenase E2

bltD 2718 spermine/spermidine acetyltransferase

1599 bacillopeptidase $F$

carA 1199 carbamoyl-phosphate transferase-arginine (subunit A) (arginine biosynthesis)
carbamoyl-phosphate transferase-arginine (subunit B) (arginine biosynthesis)

(

CYsE 113 serine acetyltransferase (cysteine biosynthesis)

(cysteine biosynthesis)

cysK 82 cysteine synthetase A (cysteine biosynthesis)

$\begin{array}{lll}517 & \text { D-alanine racemase } \\ \text { dapA } & 1748 & \text { dihydrodipicolinate synthas }\end{array}$

2359 (diaminopimelate/lysine biosynthesis)

(diaminopimelate/lysine biosynthesis)

1747 aspartokinase / $\alpha$ and $\beta$ subunits)

epr $\quad 3939$ minor extracellular serine proteas

S 200 L-glutamine-D-fructose-6-phosphate amidotrans1878 glutamine synthetase

gItA 2014 glutamate synthase (large subunit) (glutamate gltB 2009 glutamate synthase (small subunit) (glutamate

glyA 3789 serine hydroxymethyltransferase (glycine/ser-

hisA 3584 phosphoribosylformimino-5-aminoimidazole caroxamide ribotide isomerase (histidine biosyn-

hisB 3585 imidazoleglycerol-phosphate dehydratase (histi-

hisC 2371 dine biosynthesis) biosynthesis) / tyrosine and phenylalanine

hisD 3587 histidinol dehydrogenase (histidine biosynthesis)

hisF 3583 HisF cyclase-like protein (synthesis of D-erythro-

hisG 3587 ATP phosphoribosyltransferase (histidine biosyn3585 amidotransferase (histidine biosynthesis)
thesis)

hisl 3583 phosphoribosyl-AMP cyclohydrolase / phosphoribosyl-ATP pyrophosphohydrolase (histidine biosynthesis

hom 3315 homoserine dehydrogenase (threonine/methionhutG 4045 formimynthesis 4041 histidase (histidine utilization)

hutl 4044 imidazolone-5-propionate hydrolase (histidine utihutU 4042 lization)

ilvA 2293 threonine dehydratase (isoleucine biosynthesis) 2896 acetolactate synthase (large subunit)

2894 ketol-acid reductoisomerase (valine/isoleucine biosynthesis) 2302 dihydroxy-acid dehydratase (valine/isoleucine

2894 acetolactate synthase (small subunit) 


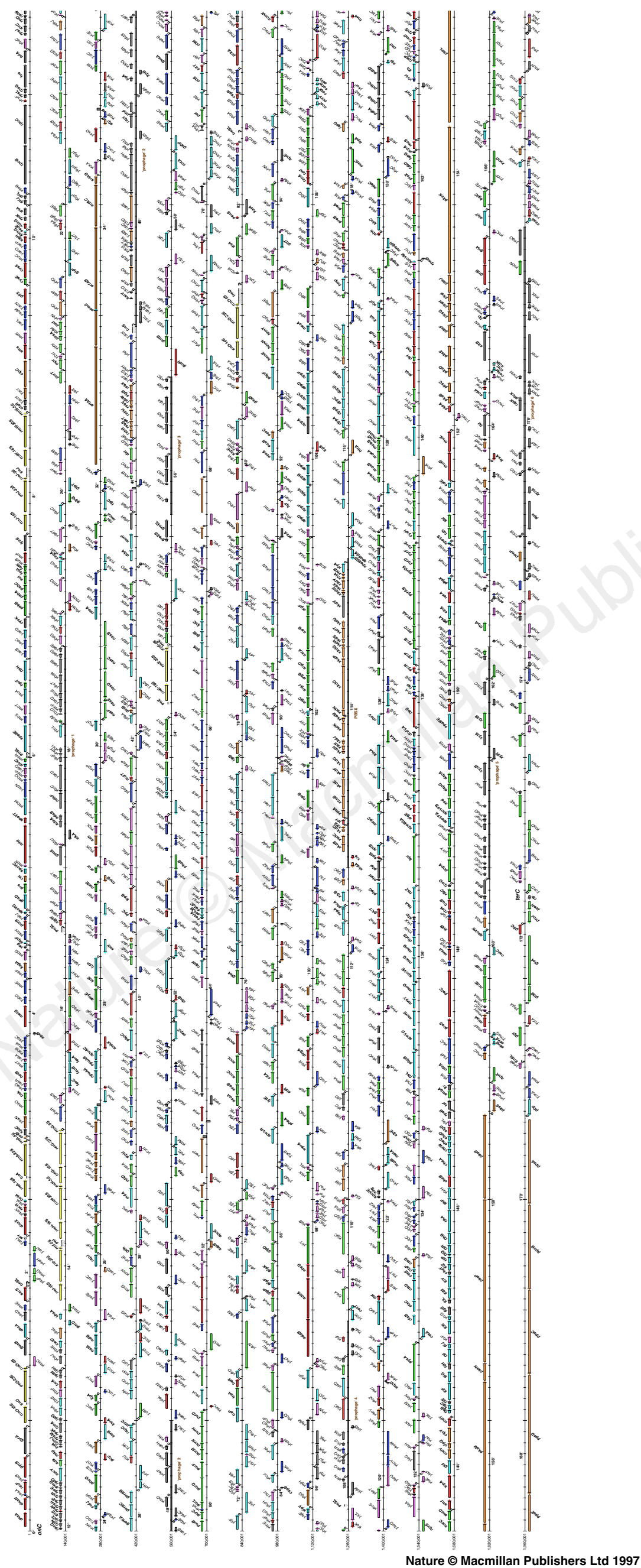




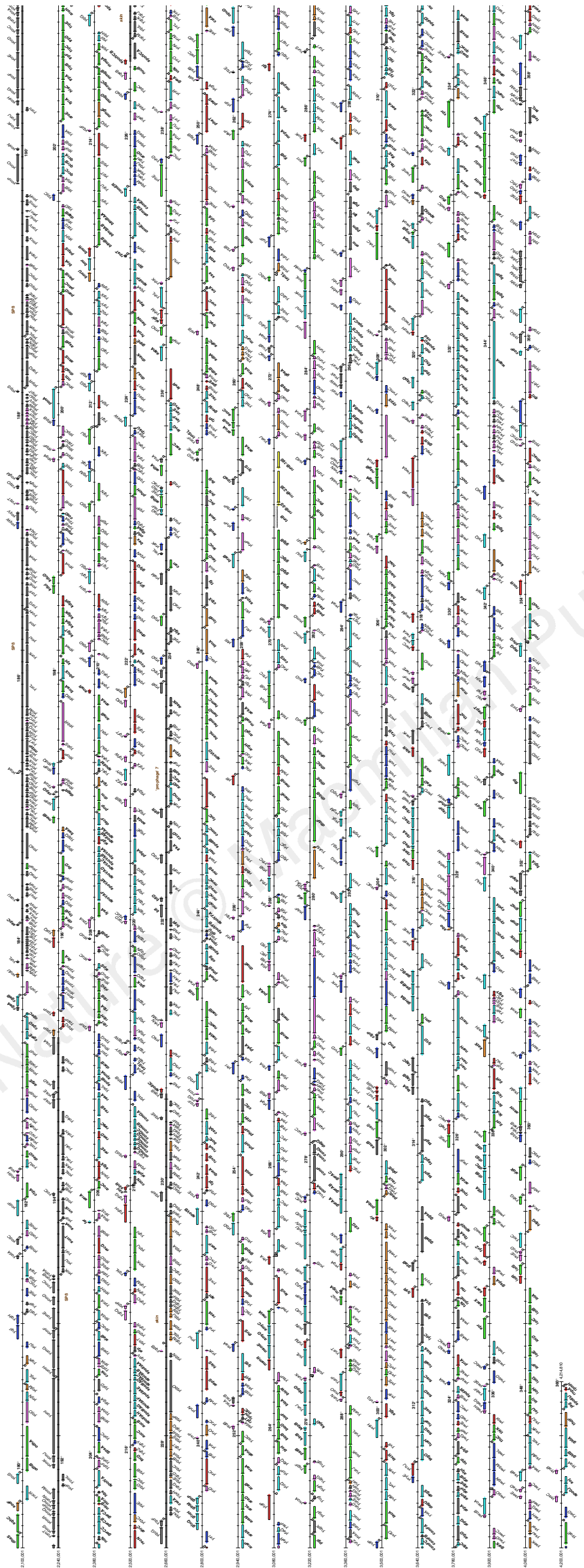


Table 1. (continuation) Functional classification of the Bacillus subtilisprotein-coding genes.

iolA $\quad 4083 \begin{aligned} & \text { (valine/isoleucine biosynthesis) } \\ & \text { methylmalonate-semialdehyde dehydrogenase }\end{aligned}$

ipi $\quad 1189$ (valine metabolism)

$\begin{array}{lll}\text { ipi } & 1189 & \text { intracellular proteinase inhibitor } \\ \text { ispA } & 1386 & \text { major intracellular serine protease } \\ \text { kbl } & 1771 & \text { 2-amino-3-ketobutyrate CoA ligase }\end{array}$

leuA 2893 2-isopropylmalate synthase (leucine biosynthe-

leuB 2891 3-isopropylmalate dehydrogenase (leucine

leuC 2890 3-isopropylmalate dehydratase (large subunit)

leuD 2889 3-isopropylmalate dehydratase (small subunit)

IySA 2437 diaminopimelate decarboxylase (lysine biosyn-

IySC 2910 thesis)

metB 2305 (diaminopimelate/lysine biosynthesis)

metC 1385 biosynthesis)

metK $3128 \begin{aligned} & \text { (methionine biosynthesis) } \\ & S \text {-adenosylmethionine synthetase }\end{aligned}$

$\mathrm{mpr} \quad 245$ extracellular metalloprotease

nasB 362 assimilatory nitrate reductase (electron transfer

nasC 360 assimilatory nitrate reductase (catalytic subunit)

$\begin{array}{lll}\text { nasD } & 358 & \text { assimilatory nitrite reductase (subunit) } \\ \text { nasE } & 355 & \text { assimilatory nitrite reductase (subunit) }\end{array}$

nprB $\quad 1186$ extracellular neutral protease B

$\begin{array}{lll}n p r E & 1541 & \text { extracellular neutral metalloprotease } \\ \mathrm{nrgB} & 3757 \text { nitrogen-regulated PII-like protein }\end{array}$

1472 aminotransferase

3228 aminotransferase
patB

pheA 2851 prephenate

pheB 2852 chorismate mutase (phenylalanine biosynthe-

proA

thesis)

$\begin{array}{lll}\text { proB } & 1378 & \gamma \text {-glutamyl kinase (proline biosynthesis) } \\ \text { proH } & 2017 \text { involved in proline biosynthesis (salt-inducible) }\end{array}$

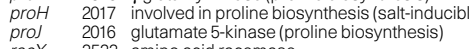

racX 3533 amino acidracemase

3879 pyrroline-5 carboxylate dehydrogenase (argi-

rocB

TOCD

rocF

serC

tdh

thrB

trpA

$\operatorname{trp} B$

$\operatorname{trpC}$

$\operatorname{trpD}$

trpE
trpF

tyrA

ure $A$
ure $B$

ure

vor 3907 minor extracellular serine protease

$\begin{array}{lll}y a a O & 38 & \text { lysine decarboxylase } \\ y b g E & 259 & \text { branched-chain amino acid aminotransferase }\end{array}$

$\begin{array}{lll}\text { ybg } & 265 & \text { glutaminase } \\ \text { ybgC } & 290 & \text { asparaginase }\end{array}$

$\begin{array}{lll}y c c C & 290 & \text { asparaginase } \\ \text { ycgM } & 344 & \text { proline oxidase }\end{array}$

ycgN 345 1-pyrroline-5-carboxylate dehydrogenase

yClE 415 prolyl aminopeptidase

$\begin{array}{lll}\text { yCIM } & 432 & \text { homoserine dehydrogenase } \\ y C n G & 441 & 4 \text {-aminobutyrate aminotransferase }\end{array}$

ycnH 443 succinate-semialdehyde dehydrogenase

YCSA 452 3-isopropylmalate dehydrogenase

$\begin{array}{lll}\text { yCSI } & 459 & \text { allophanate hydrolase } \\ \text { yerD } & 718 & \text { glutamate synthase (ferredoxin) }\end{array}$

yerM 729 amidase

$\begin{array}{ll}\text { yhaA } & 1081 \text { aminoacylase } \\ \text { yhdR } & 1034 \text { aspartate aminotransferase }\end{array}$

yisK 1152 5-oxo-1,2,5-tricarboxilic-3-penten acid decarboxylase

$\begin{array}{lll}\text { yisO } & 1157 & \text { asparagine synthase } \\ \text { yisW } & 1167 & \text { opine aminotransferase } \\ \text { yibG } & 1231 \text { oligoendopeptidase }\end{array}$

yjbG $\quad 1231$ oligoendopeptidas

$\begin{array}{ll}1258 & \text { cystathionine } \gamma \text {-synthase } \\ \text { yjcl } & 1259 \text { cystathionine } \beta \text {-lyase }\end{array}$

KeA 1359 pyrroline-5-carboxylate reductase

YKrV 1425 aspartate aminotransferase

1488 tetrahydrodipicolinate succinylase

1489 hippurate hydrolase

1607 acetylornithine deacetylase

yloW 1658 phosphoglycerate dehydrogenase

yIpA 1658 L-serine dehydratase

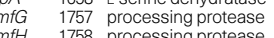

$\begin{array}{lll} & 1758 & \text { processing protease } \\ \mathrm{M} F \mathrm{H} & 1742 \text { processing protease }\end{array}$

ynal 1885 phosphoribosylanthranilate isomerase

YnCD 1898 alanine racemase

yodT 2145 adenosylmethionine aminotransferase

YPCA 2403 glutamate dehydrogenase

$\begin{array}{lll}\text { ypwA } & 2321 \text { carboxypeptidase } \\ \text { yqel } & 2644 \text { dihydrodipicolinate reductas }\end{array}$

$\begin{array}{lll}\text { yqel } & 2644 \text { dihydrodipicolinate reductios } \\ \text { yqhl } & 2549 \text { aminomethyltransferase }\end{array}$

$\begin{array}{lll}2547 & \text { glycine dehydrogenase }\end{array}$

yqhS 2539 3-dehydroquinate dehydratase
yqiT 2503 leucine dehydrogenase

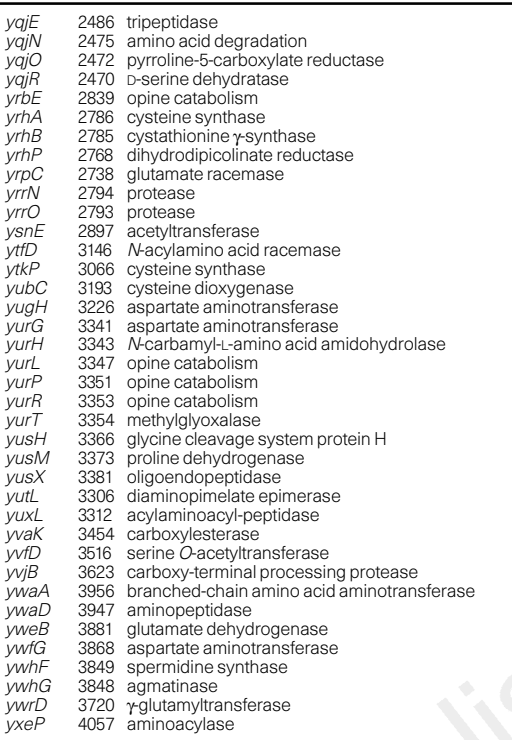

11.3

METABOLISM OF NUCLEOTIDES AND NUCLEIC

ACIDS ........................

$\begin{array}{lll}\text { adk } & 146 & \text { adenylate kinase } \\ \text { apt } & 2823 & \text { adenine phosphoribosyltransferase } \\ \text { cdd } & 2611 \text { cytidine/deoxycytidine deaminase }\end{array}$

cmk 2396 cytidylate kinase

ctrA 3811 CTP synthetase (pyrimidine biosynthesis)

deoD 2135 purine nucleoside phosphorylase (purine nucle-

oside salvage)

$4051 \begin{aligned} & \text { deoxyribose-phosphate aldolase } \\ & \text { (nucleotide/deoxyribonucleotide catabolism) }\end{aligned}$

drm 2448 phosphodeoxyribomutase (purine nucleoside

salvage)

$\begin{array}{lll}\text { guaA } & 692 & \text { GMP sylthelashosphate dehydrogenase (GMP } \\ \text { guab } & 16 & \text { inositol-monophosp }\end{array}$ biosynthesis

hipO 3000 hippurate hydrolase

hprT $\quad 76$ hypoxanthine-guanine phosphoribosyltransferase (purine salvage)

$\begin{array}{lll}\text { ndk } & 2381 & \text { nucleoside diphosphate kinase } \\ \text { nin } & 372 & \text { inhibitor of the DNA degrading activity of NucA }\end{array}$

$\begin{array}{lll}\text { nim } & 372 & \text { inhibitor of the DNA degrading activity of NucA } \\ \text { rrdE } & 1868 & \text { ribonucleoside-diphosphate reductase (major }\end{array}$

nrdF

nucA

subunit)
ribonucleoside-diphosphate reductase (minor subunit)

nucB 2652 sporulation-specific extracellular nuclease

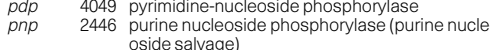

pnpA 1739 polynucleotide phosphorylase

prs 58 phosphoribosyl pyrophosphate synthetase

purA 4156 (nucleotide biosynthesis)

456 adenylosuccinate synthe (AMP biosynthe-

purB 700 adenylosuccinate lyase (purine biosynthesis)

purC 701 phosphoribos

purD $710 \begin{aligned} & \text { amide synthetase (purine biosynthesis) } \\ & \text { phosphoribosylglycinamide synthetase (purine }\end{aligned}$

purE biosynthesis)

(purinhoribosylaminoimidazole carboxylase

708 ferase (purine biosynthesis)

8 phosphoribosylaminoimidazole carboxy formy cyclohydrolase (purine biosynthesis)

purk 699 phosphoribosylaminoimidazole carboxylase II

purL 702 (purine biosynthesis)

purL $\quad 702$ phosphoribosylformylglycinamidine synthetase

purM 706 phosphoribsythesis)

(purine biosynthesis)

purN 708 phosphoribosylglycinamide formyltransferase

purQ $703 \begin{aligned} & \text { (purine biosynthesis) } \\ & \text { phosphoribosylformylglycinamidine synthetase }\end{aligned}$

T 244 (purine biosynthesis)

purT 244 phosphoribosylglycinamide formyltransferase 2

pyrA

pyrAB

pyr $B$

pyrC

pyrE

pyrF

relA

(

tdk 3802 thymidine kinase

1901 thymidylate synthase A (deoxyribonucleotide

thy $B 2297 \begin{aligned} & \text { biosynthesis) } \\ & \text { thymidylate synthase B (deoxyribonucleotide }\end{aligned}$

mk $\quad 39$ biosynthesis)

udk 2792 uridine kinase (pyrimidine salvage)

3788 uracil phosphoribosyltransferase (pyrimidine salvage)

\section{xpt 2319 xanthine phosp}

$\begin{array}{lll}\text { yaaF } & 23 & \text { deoxypurine kinase subunit } \\ \text { yaaG } & 24 & \text { deoypurine kinase }\end{array}$

yabR 70 polyribonucleotide nucleotidyltransferase

yerA 713 adenine deaminase 2 '-phosphodiesterase

yhaM 1069 CMP-binding factor

yhiry 991 5'-nucleotidase

yjbM 1236 GTP pyrophosphokinase

YKKE 1377 formyltetrahydrofolate deformy as

$y / b B \quad 1565$ IMP dehydrogenase

$\begin{array}{lll}y / O D & 1641 & \text { guanylate kinase } \\ y \text { maA } & 1868 \text { ribonucleoprotei }\end{array}$

yncB 1895 microceccal nuclease

1899 deoxyuridine 5'-triphosphate pyrophosphatase

unit)

yosO $2164 \begin{aligned} & \text { ribonucleoside-diphosphat) } \\ & \text { unit) }\end{aligned}$

$\begin{array}{lll}\text { yosP } & 2161 & \begin{array}{l}\text { ribonucleoside-diphosphate reductase ( } \beta \text { sub- } \\ \text { unit) }\end{array} \\ \text { yosS } & 2159 & \text { deoxyuridine } 5 \text { 'triphosphate nucleotidohydro- }\end{array}$

ypfD 2395 ribosomal protein $\$ 1$ homologue

yqiC 2528 exodeoxyribonuclease VII (large subunit)

yrdF 2730 ribonuclease inhibitor
yrrl 2787 purine nucleoside phosphorylase

yumD 3302 GMPreductase

yunH 3328 allantoinase

$\begin{array}{lll}\text { yunL } & 3332 & \text { uricase } \\ \text { yurl } & 3343 \text { ribonucleas }\end{array}$

ywaC 3949 GTP-pyrophosphokinase

II.4 METABOLISM OFLIPIDS

accA 2988 acetyl-CoA carboxylase ( $\alpha$ subunit) (Iong-chain

accB $2531 \begin{aligned} & \text { fatty acid biosynthesis) } \\ & \text { acetyl-CoA carboxylase (biotin carboxyl carrie }\end{aligned}$

accC 2531 subunit) (long-chain fatty acid biosynthesis)

$\begin{aligned} & \text { accC } 2531 \text { acetyl-CoA carboxylase (biotin carboxylase } \\ & \text { subunit) (long-chain fatty acid biosynthesis) }\end{aligned}$

acdA 3813 acyl-CoA dehydrogenase

cdsA 1721 phosphatidate cytidylyytransferasynthesis)

dgkA 2611 diacylglycerol kinase (phospholipid biosynthe

fabD 1663 malonyl CoA-acyl carrier protein transacylase

fabG $1664 \begin{aligned} & \text { (fatty acid biosynthesis) } \\ & 3 \text {-ketoacyl-acyl carrier protein reductase (fatty }\end{aligned}$

acid biosynthesis)

glpQ 234 glycerophosphoryl diester phosphodiesterase

IcfA (glycerol metabolism)

metabolism)

$\begin{array}{lll}\operatorname{lip} A & 292 & \text { lipase } \\ \operatorname{lipB} & 910 & \end{array}$

mmgA 2513 acetyl-CoA acetyltransferase

CoA dehydrogenase

$\begin{array}{lll}m m g C & 2511 & \text { acyl-CoA dehydrogenase } \\ \text { nap } & 593 \text { carboxylesterase NA }\end{array}$

pgsA 1762 phosphatidylglycerophosphate synthase

plsX 1662 involved in fatty acid/phospholipid synthesis

pnbA 3530 p-nitrobenzyl esterase

(phospho-

pSSA 248 phosphatidylserine synthase (phospholipid

biosynthesis)

sqhe 2101 squalene-hopene cyclase (hopanoid metabo-

ybfK 247 carboxylesterase

$\begin{array}{lll}\text { yclB } & 412 & \text { phenylacrylic acid decarboxylase } \\ y d b M & 505 & \text { butyyl-CoA dehydrogenase }\end{array}$

$y d c B \quad 515$ holo-acyl-carrier protein synthase

$\begin{array}{lll}\text { yfjR } & 871 & \text { 3-hydroxyisobutyrate dehydrogenase } \\ \text { yhaR } & 1061 & 3 \text {-hydroxbutyryl-CoA dehydratase }\end{array}$

yhdO 1031 1-acylglycerol-3-phosphate $O$-acyltransferase

yhfB 1093 3-oxoacyl-acyl-carrier protein synthase

yhfJ 1099 lipoate-protein ligase

1100 long-chain fatty-acid-CoA ligase
yhfS $\quad 1110$ acetyl-CoA C-acetyltransferase

yhfT 1111 long-chain fatty-acid-CoA ligase

yis $P \quad 1159$ phytoene synthase

yjaX 1208 3-oxoacyl-acyl-carrier protein synthase

yjaY 1209 3-oxoacyl-acyl-carrier protein synthase

HoW 1268 3-oxoacyl-acyl-carrier protein reductase

ykhA 1372 acyl-CoA hydrolase

yKWC 1465 3-hydroxyisobutyrate dehydrogenase

$\begin{array}{lll}\text { ymfl } & 1759 & \text { 3-oxoacyl-acyl-carrier protein reductas } \\ \text { yngF } & 1951 & \text { 3-hydroxbutyryl-CoA dehydratase } \\ \text { yngG } & 1952 & \text { hydroxymethylglutaryl-CoA lyase }\end{array}$

yngl 1955 long-chain acyl-CoA synthetase

1957 butyryl-CoA dehydrogenase

yocE 2089 fatty-acid desaturase

yodR 2143 butyrate-acetoacetate CoA-transferase

$\begin{array}{lll}\text { yodS } & 2144 & 3 \text {-oxoadipate CoA-transferase } \\ \text { yoxD } & 2019 & 3 \text {-oxoacyl-acyl-carrier protein reductase }\end{array}$

yqiD 2526 geranyltranstransferase

yqik 2514 glycerophosphodiester phosphodiesterase

yqiU 2502 branched-chain fatty-acid kinase

yqjQ 2471 ketoacyl reductase

ysiB 2917 3-hydroxbutyryl-CoA dehydratase

ytkK 3011 3-oxoacyl-acyl-carrier protein reductase

$\begin{array}{lll}\text { ytpA } & 3123 & \text { lysophospholipase } \\ \text { yusJ } & 3368 \text { butyryl-CoAdehydrogenase }\end{array}$

yusK 3369 acetyl-CoA C-acyltransferase

$\begin{array}{lll}\text { yusL } & 3372 & \text { 3-hydroxyacyl-CoAdehydrogenase } \\ \text { yusQ } & 3376 \text { acyloate catabolism }\end{array}$

$\begin{array}{lll}\text { yusQ } & 3376 & \text { acyloate catabolism } \\ \text { yusR } & 3376 & 3 \text {-oxoacyl-acyl-carrier protein reductase }\end{array}$

yusS 3377 3-oxoacyl-acyl-carrier protein reductase

yvaG 34503 -oxoacyl-acyl-carrier protein reductase

yvrD 3404 ketoacyl-carrier protein reductase

ywfH 3866 3-oxoacyl-acyl-carrier protein reductas

ywhB 3853 4-oxalocrotonate tautomerase

$\begin{array}{lll}\text { WWiE } & 3822 \text { cardiolipin synthetase } \\ \text { ywiE } & 3816 \text { cardiolipin synthetase }\end{array}$

$\begin{array}{lll}\text { YWjE } & 3816 & \text { cardiolipin synthetase } \\ \text { ywnE } & 3762 \text { cardiolipin synthase }\end{array}$ 
ywPB 3743 hydroxymyristoyl-(acyl carrier protein) dehy-

$\begin{array}{lll}\text { yxjD } & 4001 & \text { dratase } \\ \text { yxjE } & 4001 & 3 \text {-oxoadipate CoA-transferase } \\ & & \end{array}$

II.5 METABOLISM OF COENZYMES AND PROSTHETIC

gsaB $\quad 943$ lism)

hemA 2878 glutamyl-tRNA reductase (porphyrin biosynthe

hemB $2874 \delta$-aminolevulinic acid dehydratase (porphyrin

hemC $2876 \begin{aligned} & \text { biosynthesis) } \\ & \text { porphobilinogen deaminase (porphyrin biosyn- }\end{aligned}$

hemD 2875 uroporphyrinogen III cosynthase (porphyrin

hemE $1086 \begin{aligned} & \text { biosynthesis) } \\ & \text { uroporphyrinogen III decarboxylase (porphyrin }\end{aligned}$

hemH 1087 fiorynthesis)

hemL 2873 glutamate-1-semialdehyde 2,1-aminotransferase

hemN $2630 \begin{aligned} & \text { (porphyrin biosynthesis) } \\ & \text { coproporphyrinogen Ill oxidase (porphyrin }\end{aligned}$

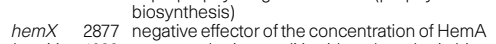

hemY 1088 protoporphyrinogen IX oxidase (porphyrin biosyn-

menB 3149 dihydroxynapthoic acid synthetase

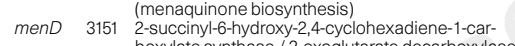

menE $3148 \begin{gathered}\text { (menaquinone biosynthesis) } \\ \text { O-succinylbenzoic acid-CoA ligase }\end{gathered}$

menF $3153 \begin{aligned} & \text { (menaquinone biosynthesis) } \\ & \text { menaquinone-specific isochorismate synthase }\end{aligned}$

moaB 3014 molybdopterin precursor biosynthesis

moaD 1499 molybdopterin converting factor (subunit 1)

moaE 1498 molybdopterin converting factor (subunit 2)

mobB 1495 molybdopterin-guanine dinucleotide biosynthesis

moeA 1497 molybdopterin biosynthesis protein

mtrA 2385 GTP cyclohydrolasel (tetrahydrofolate biosynthesis)
quinolinate synthetase (quinolinate biosynthesis)

nadB 2849 L-aspartate oxidase (quinolinate biosynthesis)

nadC 2847 nicotinate-nucleotide pyrophosphorylase

nadE $338 \quad \mathrm{NH}_{3}$-dependent NAD+ synthetase (NAD biosyn-

narA

nas

nifs
pabA

isochorismatase

$\begin{array}{lll}\text { ydiA } & 640 & \text { thiamin-monophosphate kinase } \\ \text { ydiG } & 646 & \text { molybdopterin precursor biosynthesis }\end{array}$

$\begin{array}{lll}\text { ydia } & 646 & \text { molybdopterin precursor biosynt } \\ \text { yhaV } & 1058 \text { coproporphyrinogen III oxidase }\end{array}$

$\begin{array}{lll}\text { yhCB } & 979 & \text { flavodoxin } \\ \text { yhfU } & 1112 \text { biotin biosynthesis }\end{array}$ $\begin{array}{lll}\text { yhfU } & 1112 & \text { biotin biosynthesis } \\ \text { yhxA } & 1000 & \text { adenosylmethionine-8-amino-7-oxononanoate } \\ \text { aminotransferase }\end{array}$ $\begin{array}{ll}\text { yjbT } & 1245 \text { thiamin biosynthesis } \\ \text { yjbU } & 1245 \text { thiamin biosynthesis }\end{array}$

yjbV 1246 phosphomethylpyrimidine kinas

y $p B \quad 1513$ thiamin biosynthesis

$\begin{array}{lll}y K k V B & 1513 & \text { thiamin biosynthesis } \\ y V K & 1440 & 6 \text {-pyruvoyl tetrahydrobiopterin synthase } \\ y K V L & 1440 & \text { coenzyme PQQ synthesis }\end{array}$

1577 pyrimidine-thiamine biosynthesis

1633 uroporphyrin-III $C$-methyltransferase

1635 uroporphyrin-III C-methyltransferase

1954 biotin carboxylase

yodC 2127 nitroreductase

25745 -formyltetrahydrofo

2469 pantothenate kinase

$\begin{array}{ll}\text { yrrL } & 2796 \text { folate metabolism } \\ \text { yrrM } & 2795 \text { caffeoyl-CoA O-methyltransferase }\end{array}$

yueD 3265 sepiapterin reductase

3261 pyrazinamidase/nicotinamidase

$\begin{array}{lll}\text { yuiG } & 3293 & \text { biotin metabolism } \\ \text { yurB } & 3335 & \text { 4-hydroxybenzoyl-CoA reductase }\end{array}$

yurC 3338 4-hydroxybenzoyl-CoA reductase

yurD 3338 4-hydroxybenzoyl-CoA reductase

$\begin{array}{lll}\text { yutB } & 3320 \text { lipoic acid synthetase } \\ \text { ywaB } & 3950 \text { quinone biosynthesis }\end{array}$

WKE 3796 protoporphyrinogen oxidase

phoA 1018 alkaline phosphatase A

phoB 621 alkaline phosphatase III

phoD 284 phosphodiesterase/alkaline phosphatas

2615 phosphatestarvation-induced protein

36 hydrolysis of 5-bromo 4-chloroindolyl phosphate

248 alkaline phosphatase

1549 phosphate starvation inducible protein

1947 alkaline phosphatase

METABOLISM OF SULPHUR

1170 adenylylsulfate kinase
1171 sulfate adenylyltransferas

1172 phospho-adenylylsulfate sulfotransferas

1633 adenylylsulfate kinase

3293 sulfite oxidase

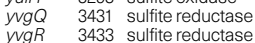

INFORMATION PATHWAYS 482

III.1

dnaA $\quad 0 \quad$ initiation of chromosome replication

$\begin{array}{ll}0 & \text { initiation of chromosome replication } \\ 2965 & \text { initiation of chromosome replication / membrane }\end{array}$

2158 attachment protein
replicative DNA helicase

2345 initiation of chromosome replication

2994 DNA polymerase III ( $\alpha$ subunit)

2963 pNAmosome component (helicase loader)

$\begin{array}{ll}2 & \text { DNA polymerase III ( } \beta \text { subunit) } \\ 27 & \text { DNA polymerase III ( } \gamma \text { and } \tau \text { sub }\end{array}$

41. DNA polymerase III ( $\delta^{\prime}$ subunit)

2975 DNA polymerase I
1727 DNA polymerase III ( $\alpha$ subunit)

1643 primosomal replication factor $Y$

1677 ribonuclease $\mathrm{H}$

2018 replication terminator protein
4199 single-strand DNA-binding protein

$\begin{array}{lll}\text { ssb } & 4199 & \text { single-strand DNA-binding prote } \\ \text { yerF } & 719 & \text { ATP-dependent DNA helicase }\end{array}$

$\begin{array}{lll}\text { yerG } & 721 & \text { DNA ligase } \\ \text { yogV } & 2192 & \text { DNAligase }\end{array}$

2179 DNA polymerase III ( $\alpha$ subunit)

$\begin{array}{lll}\text { ypcP } & 2311 & 5^{\prime}-3^{\prime} \text { exonuclease } \\ \text { ywpH } & 3740 & \text { single-strand DNA-binding protein }\end{array}$

III.2 DNARESTRICTION/MODIFICATION AND

REPAIR

adaA

204 methylphosphotriester-DNA alkyltransferase /

204 transcriptional activator of the adaAB operon

203 DNA-3-methyladenine glycosylase

$1421 O^{6}$-methylguanine DNA alkyltransferase

608 nuclease inhibitor

4198 3'-exo-deoxyribonuclease

mtbP 2172 modification methylase Bsu

mutL 1778 DNA mismatch repair

mutM 2972 formamidopyrimidine-DNA glycosidase

(2)

2345 mutator protein

106 DNA repair protein homologue
3897 uracil-DNA glycosylase

3612 excinuclease $A B C$ (subunit

3614 excinuclease ABC (subunit B)

2912 excinuclease ABC (subunit C)

2271 UV-damage repair protein

655 DNA-methyltransferase (cytosine-specific)

660 DNA restriction

935 A/G-specific adenine glycosylase

872 DNA-3-methyladenine glycosidase

1165 nuclease inhibitor

1290 mutator MutT protein

2064 DNA repair protein
2336 ATP-dependenthelicase
2329 ATP-dependenthelicase

2329 ATP-dependent he

2483 DNA-damage repair protein

2465 ATP/GTP-binding protein

2924 DNA polymerase

2922 DNA mismatch repair protein

2862 DNA repair protein
3572 mutator MutT protein

3964 DNA-3-methyladenine glycosidase

DNA RECOMBINATION

1139 ATP-dependent deoxyribonuclease (subunit A. ${ }^{17}$

1136 ATP-dependent deoxyribonuclease (subunit B

multifunctional protein involved in homologous

recombination and DNA repair (LexA-autoclea-
age)

$\begin{array}{lll} & \text { age) } \\ \text { recF } 3 & \text { DNA repair and genetic recombination }\end{array}$

recN 2522 DNA repair and genetic recombination

$r e c N$
$r e c Q$ 2408 ATP-dependent DNA helicase

Nature @ Macmillan Publishers Ltd 1997 $\begin{array}{lll}\text { recR } & 29 & \text { DNA repair and genetic recombination } \\ \text { ruvA } & 2836 \text { Hollidayjunction DNA helicase }\end{array}$

rUVB $\quad 2835$ Holliday junction DNA helicase

$S b c D \quad 1143$ exonuclease SbcD homologue

yIpB 1659 ATP-dependent DNA helicase

yocl 2095 ATP-dependent DNA helicase

york 2180 single-strand DNA-specific exonuclease

$\begin{array}{lll}\text { yahH } & 2549 & \text { SNF2 helicase } \\ \text { yrrC } & 2808 \text { conjugation transfer protein }\end{array}$

YTE 2825 single-strand DNA-specific exonuclease

III.4 DNAPACKAGING AND SEGREGATION.

$\begin{array}{ll}\text { grlA } & 1935 \text { DNA gyrase-like protein (subunit A) } \\ \text { grlB } & 1933 \text { DNA gyrase-like protein (subunit B) }\end{array}$

$\begin{array}{lll}\text { gyrA } & 7 & \text { DNA gyrase (subunit } A \text { ) } \\ \text { gyrB } & 5 & \text { DNA gyrase (subunit }\end{array}$

$\begin{array}{lll}\text { gyrB } & 5 & \text { DNA gyrase (subunit B) } \\ \text { hbs } & 2385 & \text { non-specific DNA-binding protein HBsu }\end{array}$

$\begin{array}{lll}\text { hbs } & 2385 & \text { non-specific DNA-binding protein HBsu } \\ \text { smc } & 1666 & \text { chromosome segregation SMC protein homo- }\end{array}$

logue
smf 1682 DNA processing Smf protein homologue

topA 1683 DNA topoisomerase I

$\begin{array}{lll}\text { topB } & 476 & \text { DNA topoisomerase III } \\ \text { yonN } & 2225 \text { HU-related DNA-binding protein }\end{array}$

III.5

111.5 .1
sigA

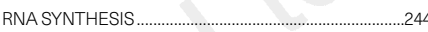

INITIATION

.19

sigB 522 RNA polymerase general stress sigma factor $\left(\sigma^{\mathrm{B}}\right)$

sigD 1716 RNA polymerase flagella, motility, chemotaxis and

sigE 1604 autolysis sigma factor $\left(\sigma^{\circ}\right)$

sigF $\quad 2443$ (early) sigma factor ( $\sigma^{\mathrm{E}}$ )(SpollGB)

SigF 2443 RNA polymerase sporulation forespore-specific

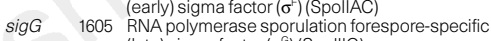

sigH $117 \begin{aligned} & \left.\text { (late) sigma factor ( } \sigma^{G}\right) \text { (SpollliG) } \\ & \text { RNA polymerase vegetative and early stationary }\end{aligned}$

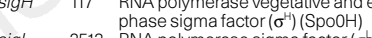

$\begin{array}{lll}s i g L & 3513 & \text { RNA polymerase sigma factor }\left(\sigma^{-}\right) \\ \text {sigV } & 2769 & \text { RNA polymerase ECF-type sigma factor }\left(\sigma^{v}\right)\end{array}$

$\begin{array}{lll}\text { sigV } & 2769 & \text { RNA polymerase ECF-type sigma factor }\left(\sigma^{w}\right) \\ \text { sigW } & 195 & \text { RNA polymerase ECF-type sigma factor }\left(\sigma^{m}\right) \\ \text { sigX } & 2414 & \text { RNA polymerase ECF-type sigma factor }\left(\sigma^{x}\right)\end{array}$

$\begin{array}{lll}\text { sigX } & 2414 & \text { RNA polymerase ECF-type sigma factor }\left(\sigma^{\prime}\right. \\ \text { sigY } & 3970 & \text { RNA polymerase ECF-type sigma factor }\left(\sigma^{r}\right.\end{array}$

$\begin{array}{lll}\text { sigZ } & 2742 & \text { RNA polymerase ECF-type sigma factor }\left(\sigma^{2}\right) \\ \text { spollIC } & 2701 & \text { RNA polymerase sporulation mother cell-specific }\end{array}$

(late) sigma factor $\left(\sigma^{k}\right)(C$-terminal half)
spoIVCB 2652 RNA polymerase sporulation mother-cell-specific

xpf 1324 (late) sigma factor $\left(\sigma^{k}\right)($ N-terminal half)
RNA polymerase PBSX sigma factor-like

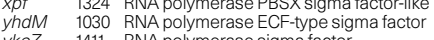

$\begin{array}{lll}\text { ykoZ } & 1411 & \text { RNA polymerase sigma factor } \\ \text { ylaC } & 1543 & \text { RNA polymerase ECF-type sigma factor }\end{array}$

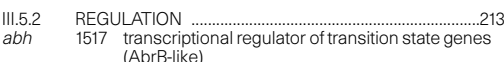

$\begin{array}{lll}\text { abrB } 45 \quad \begin{array}{l}\text { (AbrB-like) } \\ \text { transcriptional pleiotropic regulator of transition }\end{array} & \end{array}$ state genes (aprE, comK, fts $A Z, h p r, \operatorname{mot} A B, n p r E$,
pbpe, rbs, spoOH, spoVG, spoOE, tycA)

aCoR 883 transcriptional activator of the acetoin dehydroge-

nase operon (aco $A B C L$ )
ahrC 2522 transcriptional regulator of arginine metabolism

alsR 3711 transcriptional regulator of the $\alpha$-acetolactate

ansR 2456 operon (alsSD)

(Xre family)

3485 transcriptional repressor of the arabinose operon

azIB 2729 transcriptional repressor of the azIBCD operon

birA 2355 transcriptional repressor of the biotin operon (bioWAFDBI) / biotin acetyl-COA-carboxylas
thetase
transcriptional regulator of the bltD operon

$\begin{array}{lll}\text { bltR } & 2716 & \text { transcriptional regulator of the bltD operon } \\ b m r R & 2495 & \text { transcriptional activator of the bmrUR operon }\end{array}$

CCPA 3044 transcriptional regulator involved in carbon

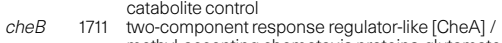
methyl-accepting chemotaxis proteins-glutamate methylesterase

cheY 1703 two-component response regulator [CheA] involved in mod
(chemotaxis)

citR 1020 transcriptional repressor of the citrate synthase

$\begin{array}{lll}\text { citT } 832 \text { gene (citA) } & \text { two-component response regulator [CitS] }\end{array}$

codY 1690 transcriptional pleiotropic repressor (expression

comA 3253 of SrfA, comK, dpp, gabP, hut, ureABC

comA 3253 two-component response regulator [ComP] of

comK $1117 \begin{aligned} & \text { late competence genes / surfactin production } \\ & \text { competence transcription factor (CTF), final }\end{aligned}$ autoregulatory control switch prior to competence development

comQ 3256 transcriptional regulator of late competence oper-

on (COMG) and surfactin expression (SrfA)

$\begin{array}{lll}\text { ctsR } 101 & \begin{array}{l}\text { transcriptional repressor of class III stress genes } \\ (C / D C, C / D P)\end{array}\end{array}$

$\operatorname{deg} A \quad 1163$ transcriptional activator involved in the degradation of glutamine phosphoribosylpyrophosphate

degU 3644 two-component response regulator [DegS] No-component response regulator [DegS]
nvolved in degradative enzyme and competence

regulation (sacB, $\operatorname{deg} Q$, comK)
deoR 4052 transcriptional repressor of the dra/ nup C/pdp

for 3831 transcriptional regulator fof

3831 transcriptional regulator of anaerobic genes

fruR 1507 transcriptional repressor of the fructose operon

gerE 2904 (fruRBAs)

glcR 3739 transcriptional repressor involved in the expres-

gICT $1456 \begin{aligned} & \text { sion of the phosphotransferase system } \\ & \text { transcriptional antiterminator essential for the }\end{aligned}$

gInR $1877 \begin{aligned} & \text { expression of the } p t s G H / \text { operon } \\ & \text { transcriptional repressor of the glutamine syn- }\end{aligned}$

glpP $\quad 1001 \begin{aligned} & \text { thetase gene }(g / n A) \\ & \text { transcriptional antiterminator and control of }\end{aligned}$

mRNA stability of $g / p D$
transcriptional activator of the glutamate synthase

gltC $2014 \begin{aligned} & \text { transcriptional } \\ & \text { operon(g/tAB) }\end{aligned}$

gltR $2725 \begin{aligned} & \text { transcriptional repressor of the glutamate syn- } \\ & \text { thase operon ( } g / t A B)\end{aligned}$

gntR $4113 \begin{aligned} & \text { transcriptional repressor of the gluconate operon } \\ & \text { (gntRKPZ) }\end{aligned}$ 
hpr

hrcA

nutp

\section{sir}

sir $\quad 3529$ transcriptional activator of competence develop-

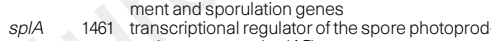

spooA $2518 \begin{aligned} & \text { uctlyase operon (splAB) } \\ & \text { two-component response regulator }[K i n C] \text { central }\end{aligned}$ for the initiation of sporulation ( $s p O O A$, abrB, $k$ in kinC, spollA, spollE, spollG) (part of phosphore-
lay: SpoOB P $>$ SpoOA P)

spoOF 3809 two-component response regulator [KinA, KinB] involved in the initiation of sporulation (part of

phosphorelay: SpoOF P P $>$ SpoOB P)
spollID 3748 transcriptional regulator of $\sigma^{\mathrm{E}}$-and $\sigma^{\mathrm{K}}$-dependen spovt 64 genes $\begin{array}{lll}\text { spovT } 64 & \begin{array}{l}\text { transcriptional positive and negative regulator of } \\ \sigma^{6} \text {-dependent genes }\end{array} \\ \text { tenA } & 1242 & \text { transcriptional regulator of extracellular enzym }\end{array}$

tenl 1243 genes (apre, npre, phoA, sacB)

251 transcriptional regulator (AraC/XylS family

$\begin{array}{lll}y b g A & 258 & \text { transcriptional regulator (GntR family) } \\ y c b B & 267 & \text { two-component response regulator }[Y c b A]\end{array}$

$\begin{array}{lll}y c b B & 267 & \text { two-component response regulator [Yco } \\ y c b G & 273 & \text { transcriptional regulator (GntR family) }\end{array}$

$\begin{array}{lll}y c b L & 278 & \text { two-component response regulator }[\mathrm{YCbM}] \\ y c c H & 296 & \text { two-component response regulator }[\mathrm{YCcG}]\end{array}$

yceK 320 transcriptional regulator (ArsR family

$\begin{array}{lll}y c g K & 341 & \text { transcriptional regulator (LysR family) } \\ y c / A & 412 & \text { transcriptional regulator (LysR family) }\end{array}$

$\begin{array}{llll}y c / J & 426 & \text { two-component response regulator [YcIK] } \\ y c n C & 438 & \text { transcriptional regulator (TetR/AcrR family) }\end{array}$

$\begin{array}{lll}\text { ycnC } & 438 & \text { transcriptional regulator (TetR/AcrR family) } \\ \text { yCnF } & 441 & \text { transcriptional regulator (GntR family) / amino }\end{array}$

yonk 449 transferase (MocR-like)

$\begin{array}{lll}\text { ycsO } & 461 & \text { transcriptional regulator (IcIR family) } \\ \text { ycxD } & 406 & \text { transcriptional regulator (GntR family) / amino }\end{array}$

yCzG $439 \begin{aligned} & \text { transferase (MocR-like) } \\ & \text { transcriptional regulator (ArsR family) }\end{aligned}$

$\begin{array}{lll}y c z G & 439 & \text { transcriptional regulator (ArsR family) } \\ y d a A & 467 & \text { transcriptional antiterminator (BglG family) }\end{array}$ $\begin{array}{lll}y d b G & 499 & \text { two-component response regulator [YdbF] } \\ y d c N & 531 & \text { transcriptional regulator (phage-related) (Xre fami- }\end{array}$ yde

yder

yjdc
yjdl
yimH
562 transcriptional regulator (AraC/XylS family) transcriptional regulator (AraC/XylS family) transferase (MocR-like) transcriptional regulator (GntR family) / amino-
transferase (MocR-like) transcriptional regulator (TetR/AcrR family) transcriptional regulator (ArsR family)
transcriptional regulator (GntR family) / aminotwo-component response regulator [ $\mathrm{YdfH}]$ transcriptional regulator (MarR family) transcriptional regulator (MarR family) transcriptional regulator (GntR family) transcriptional regulator (GntR family)
transcriptional regulator (TetR/AcrR fam transcriptional regulator (TetR/AcrR family)
two-component response regulator [YesM] transcriptional regulator (AraC/XylS fam
transcriptional regulator (MarR family) (MarR family) transcriptional regulator (Lrp/AsnC family)
transcriptional regulator (AraC/XylS family) two-component response regulator [Yfij] transcriptional regulator (MarR family) transcriptional regulator (MerR family)
transcriptional regulator (Fur family) transcriptional regulator (Fur family)
transcriptional regulator (MarR family) transcriptional regulator (MarR family)
transcriptional regulator (GntR family) 1009 two-component response regulator [YhcY] transferase (MocR-like)

33 transcriptional regulator (MerR family)

1089 transcriptional regulator (TetR/AcrR family)

129 transcriptional regulator (Lacl family)

166 transcriptional regulator (GntR family) / aminotransferase (MocR-like)
transcriptional antiterminator (Bg|G family)

277 transcriptional antiterm

1308 transcriptional regulator (Lacl family)

1391 two-component response regulator [Ykol]

transcriptional regulator (MarR family)

gulator (MarR family)

1754 transcriptional regulator (LantR family) two-component response regulator (CheY homologue)

2056 transcriptional regulator (LysR family) ly)
transcriptional regulator (AraC/XylS family)

2091 two-component response regulator [YocF

2007 transcriptional regulator (LysR family) ly)
transcriptional regulator (ArsR family)

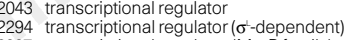
2294 transcriptional regulator ( $\sigma$-dependent)
2287 transcriptional regulator (MarR family) 2287 transcriptional regulator (PilB family)

2414 negative regulator of $\sigma^{\times}$activity (Xre family)

2657 transcriptional regulator (ArsR family)

2591 transcriptional regulator (Fur family)

2543 transcriptional regulator
2506 transcriptional regulator ( $\sigma$-dependent)

2450 transcriptional regulator (Fur family)

2746 transcriptional regulator (LysR family)

transcriptional regulator (LysR family)

2777 transcriptional regulator (TetR/AcrR family)

2704 two-component response regulator [YrkQ]

2904 transcriptional regulator (MarR family)

3008 transcriptional regulator (LysR family)

3118 transcriptional regulator (GntR family)

3113 two-component response regulator [YtsB]
3071 transcriptional regulator (DeoR family) 1 transcriptional regulator (DeoR family)
two-component response regulator [YufL]

201 transcriptional regulator (DeoR family)

3345 transcriptional regulator (GntR family)

3374 transcriptional regulator (MarR family)

3466 transcriptional regulator (ArsR family)

3488 transcriptional regulator (LysR family)
3567 two-component response regulator [YvcQ]

3558 transcriptional regulator (Lacl family)
540 transcriptional regulator (TetR/AcrR family)

3509 transcriptional regulator (GntR family)

3496 two-component response regulator [YvfT]

3646 transcriptional regulator
3617 transcriptional regulator (TetR/AcrR family)

3596 transcriptional regulator (GntR family)

385 two-component response regulator [YvGB]
394 two-component response regulator [YvGE]

3409 two-component response regulator (Y
3945 transcriptional regulator (MarR family)

3932 transcriptional regulator (LysR family)

transcriptional regulator (LysR family)

3853 transcriptional regulator (MarR family)
3748 transcriptional regulator (MarR family)

3720 transcriptional regulator (Lrp/AsnC family)

3720 transcriptional regulator (Lrp/AsnC fam
3693 transcriptional regulator
4109 transcriptional regulator (MarR family)

4072 two-component response regulator [Y $[\mathrm{XdK}]$

3993 two-component response regulator [YXjM

3991 transcriptional regulator (LysR family)
4197 transcriptional regulator (Lacl family)

4189 transcriptional regulator (MerR family)

4180 transcriptional regulator (LysR family)
4154 two-component response regulator [YycG]
4122 transcriptional regulator (GntR family)

ELONGATION.................. 8

2791 transcription elongation factor

2356 transcription-repair coupling factor

149 RNA polymerase ( $\alpha$ subunit

126 RNA polymerase ( $\beta^{\prime}$ subunit)

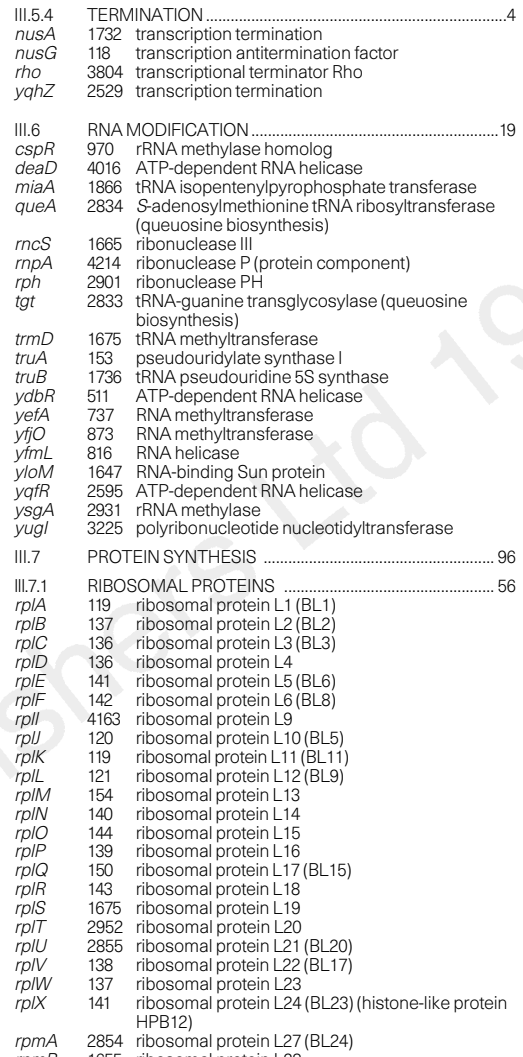

$\begin{array}{lll}r p m A & 2854 & \text { ribosomal protein L27 (BL24) } \\ \text { rpmB } & 1655 \text { ribosomal protein L28 }\end{array}$

$\begin{array}{lll}r p m C & 140 & \text { ribosomal protein } \mathrm{L} 29 \\ r p m D & 144 & \text { ribosomal protein } \mathrm{L} 30(\mathrm{~B} L 27)\end{array}$

PME 3802 ribosomal protein L31

rpmG 117 ribosomal protein L33

rpmH 4215 ribosomal protein L34

rpm/ 2952 ribosomal protein L35

rpmJ 148 ribosomal protein L36 (ribosomal protein B)

rPSC 139 ribosomal protein S3 (BS3)

rPSE 143 ribosomal protein S5

$\begin{array}{lll}\text { rpSF } & 4199 & \text { ribosomal protein S6 (BS9) } \\ \text { rpsG } & 130 & \text { ribosomal protein S7 (BS7) }\end{array}$

rpsH 142 ribosomal protein S8(BS8)

rpsl 154 ribosomal protein S9

$\begin{array}{lll}\text { rpSJ } & 135 & \text { ribosomal protein S10 (BS13) } \\ \text { rpsK } & 148 & \text { ribosomal protein S11(BS11) }\end{array}$

$\begin{array}{lll}r P S L & 130 & \text { ribosomal protein S12(BS12 } \\ \text { rpsM } & 148 & \text { ribosomal protein S13 }\end{array}$

rpsN 142 ribosomal protein S14

rpsO 1738 ribosomal protein S15(BS18)

rpsP 1673 ribosomal protein S16 (BS17)

$\begin{array}{lll}r p S Q & 140 & \text { ribosomal protein S17 (BS16) } \\ r p S R & 4198 & \text { ribosomal protein S18 }\end{array}$

$\begin{array}{lll}\text { rpsS } & 138 & \text { ribosomal protein S19(BS19) } \\ \text { rpsT } & 2635 & \text { ribosomal protein S20 (BS20) }\end{array}$

rpsU 2620 ribosomal protein S21

yhzA 965 ribosomal protein S14

$\begin{array}{lll}y / x Q & 1733 & \text { ribosomal protein L7AE family } \\ y v y D & 3631 & \text { ribosomal protein S30AE family }\end{array}$

11.7. AMINOACYL-TRNASYNTHETASES

alaS
args
3834 arginyl-tRNA synnthetase

asnS 2347 asparaginyl-tRNA synthetase

aspS
2816 aspartyl-tRNA synthetase
cysS
113 cysteinyl-tRNA synthetase

gltt 111 glutamyl-tRNA synthetase

$\begin{array}{ll}\text { glyQ } & 2608 \text { glycyl-tRNA synthetase ( } \alpha \text { subunit) } \\ \text { glyS } & 2607 \text { glycyl-tRNA synthetase ( } \beta \text { subunit) }\end{array}$

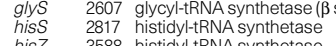

ileS 1613 isoleucyl-tRNA synthetase

leuS 3104 leucyl-tRNA synthetase

lysS 89 lysyl-tRNA synthetase

pheS 2930 mhennylalanyl-ta synthetase

pheT 2929 phenylalanyl-tRNA synthetase ( $\beta$ subunit)

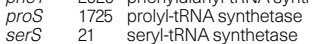

thrs 2960 threonyl-tRNA synthetase (major)
thrz 3855 threonyl-tRNA synthetase (minor)

trpS 1219 tryptophanyl-tRNA synthetase

$\begin{array}{ll}\text { tyrS } & 3037 \\ \text { tyrz } & 3946 \text { tyrosyl-thNA synthetase (major) } \\ \text { tyrosyl-tRNA synthetase (minor) }\end{array}$

valS 2869 valyl-tRNA synthetase
ytpR 3052 phenylalanyl-tRNA synthetase ( $\beta$ subunit)

III.7.3 INITIATION

fmt 1646 methionyl-tRNA formyltransferase

$\begin{array}{lll}\text { Imt } & 1646 & \text { methionyl-thNA for } \\ \text { inf } & 148 & \text { initiation factor IF-1 } \\ \text { inf } & 1733 & \text { initiotion fat }\end{array}$

IinfB
infC $\quad 2952$ initition factor IF-2

$r b f A$
$y k r S$
1723

III.7.4 ELONGATION.

efp
fus
fus 


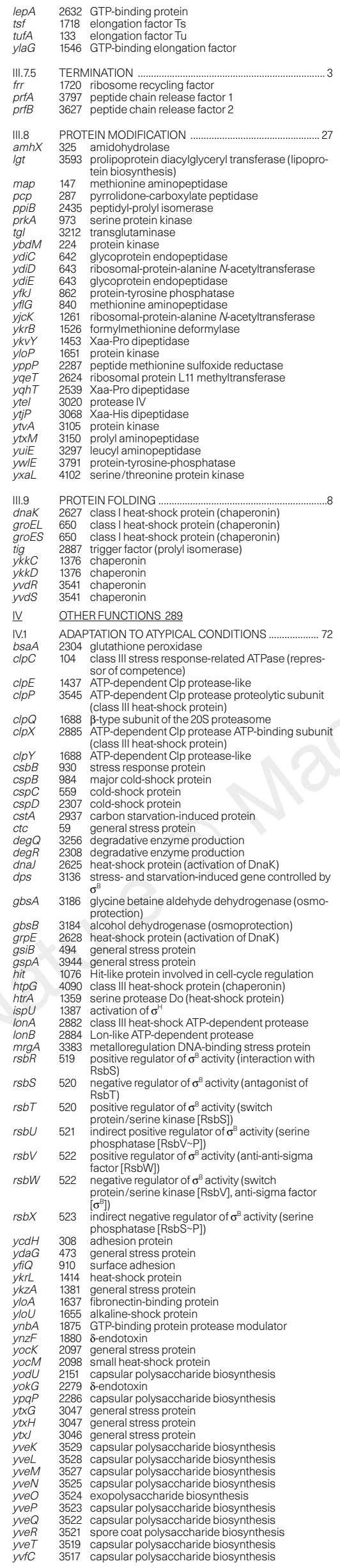

YVIE 3515 spore coat polysaccharide biosynthesis

yvtB 3384 serine protease Do

ywaD 3732 capsular

WWE 3731 capsular polysaccharide biosynthesis

3700 capsular polyglutamate biosynthes

3698 capsular polyglutamate biosynthes

WWA 3698 capsular polyglutamato biosynthesis

IV.2 DETOXIFICATION

aadK 2736 aminoglycoside 6-adenylyltransferase

ahpC 4118 alkyl hydroperoxide reductase (small subunit)

ahpF 4119 alkyl hydroperoxide reductase (large subunit)/

bmrU 2493 multidrug resogenase

cah $\quad 342$ cephalosporin C deacetylase

cypX 3603 cytochrome P450-like enzyme

katA 960 vegetative catalase 1

katB 4009 catalase 2 dimethyladen

mmr 3857 methylenomycin A resistance protein

padC 3532 ferulate decarboxylase $\begin{array}{lll}\text { penP } & 2048 & \beta \text {-lactamase } \\ \text { pksS } & 1859 & \text { hydroxylase of the polyketide produced by the }\end{array}$

pks cluster
superoxide dismutase

sodF 2103 superoxide dismutas

the $\quad 4212$ thiophen and furance leader peptide

tmrB 339 tunicamycin resistance

yaaN 36 toxic cation resistance

ybbE $\quad 190 \quad \beta$-lactamase

$y b f O$
$y b x l$
$y c b j$

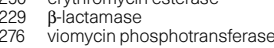

283 toxic cat

312 tellurium resistance protein

313 tellurium resistance protein

ceF 314 tellurium resistance protein

$\mathrm{ceH} \quad 316$ toxic anion resistance prote

ydbD
$y d f B$
$y d h E$

yerp

yetM

496 manganese-containing catalas

581 antibiotic resistance protein

732 macrolide glycosyltransferase

790 salicylate 1-monooxygenase
792 cytochrome P450 / NADPH-cytochrome P45

yfIM $836 \quad \begin{aligned} & \text { reductase } \\ & \text { nitric-oxide synthas }\end{aligned}$

ffnC $\quad 804$ fosmidmycin resistance protein

$\begin{array}{lll}\text { ygaF } & 943 & \text { thiol-specific antiox } \\ \text { yhjG } & 1122 & \text { monooxygenase }\end{array}$

yisY 1169 chloride peroxidas

1291 monooxygenase

1292 macrolide glycosyltransferase

1366 immunity to bacteriotoxin

$1375 \mathrm{~N}$-acetyltransferase
1410 toxic anion resistance protein

1916 fosfomycin resistance protein

1916 fosfomycin resistance prote
2088 immunity to bacteriotoxins

2117 macrolide glycosyltransferase

2115 superoxide dismutase

2281 aminoglycoside $N 3$ '-acetyltransferase

2655 arsenate reductase

2596 penicillin tolerance
2776 cytochrome P450 / NADPH-cytochrome P450

2776 cytochrome

2736 2-nitropropane dioxygenase

$\begin{array}{ll}y r p B & 273017 \\ y \operatorname{tgl} & \text { thiol peroxidase }\end{array}$

$\begin{array}{lll}\text { ytnj } & 3002 & \text { nitrilotriacetate monooxygenase } \\ \text { yubB } & 3195 & \text { bacitracin resistance protein (undecaprenol }\end{array}$

3366 arsenate reductase

YVbT 3487 alkanal monooxygenas

WdP 3543 reticuline oxidase

WwnH 3760 phosphinothricin acetyltransferase

yxel 4062 penicillin amidase

$\begin{array}{lll}\text { yxeK } & 4061 & \text { monooxygenase } \\ \text { yyaR } & 4185 & \text { streptothricine acetyl-transferase }\end{array}$

V.3 ANTIBIOTIC PRODUCTION.

pksB $\quad 1782$ involved in polyketide synthesis

PKSD 1785 in

PKSE 1785 involved in polyketide synthesis

DKSF 1788 involved in polyketide synthesis

pksG 1789 involved in polyketide synthesis

pksH 1790 involved in polyketide synthesis

pksJ 1792 involved in polyketide synthesis

pksK 1794 polyketide synthase

pksL 1808 polyketidesynthase

pKSP 1835 polyketide synthase

PKSR 1850 polyketide synthase

DPSA 1997 peptide synthetase

PDSB 1990 peptide synthetase

PPSD 1974 peptide synthetase

PDSE 1963 peptidesynthetose

sbo 3835 subtilosin A

stp 408 surfactin production

SUA 377 surfactin synthetase / competence

(3) surfactin synthetase/competence

( 398 surfactin synthetase/competence

sunA 2269 sublancin 168 lantibiotic antimicrobial precurso sublancin

yomB 2264 bacteriocin

$\begin{array}{lll}\text { yukL } & 3282 \text { antibiotic synthetase } \\ \text { yukM } & 3283 \text { antibiotic synthetase }\end{array}$

V.4 PHAGE-RELATED FUNCTIONS

codV 1687 integrase/recombinase

xh/A 1346 involved in cell lysis upon induction of PBSX

th/B 1346 hydrolysis of 5-bromo 4-chloroindolyl phosphate

$x k d A$
$x k d B$

upon induction o PB
1320 PBSX prophage
1321 PBSX prophage
xkdC 1322 PBSX prophage

XkdE 1327 PBSX prophage

$x k d F \quad 1328$ PBSX prophage

XkdG 1329 PBSX prophage

xkdl 1331 PBSX prophag

XKdK 1332 PBSX prophage

$x k d N 1334$ PBSX prophage

XkdO 1334 PBSX prophage

$\begin{array}{lll}1338 & \text { PBSX prophage } \\ X d Q & 1339 & \text { PBSX prophag }\end{array}$

XkdR 1340 PBSX prophag

xkdS 1340 PBSX prophag

XkdU 1342 PBSX prophage

$\begin{array}{lll}x k d X & 1345 & \text { PBSX prophag } \\ x k d 4 & 1345 \text { PBSX prophage }\end{array}$

$x k d Y 1345$ PBSX prophage lytic exoenzyme

XImA 1325 PBSX

$\begin{array}{lll}x t m B & 1325 & \text { PBSX terminase (large subunit) } \\ x t r A & 1324 & \text { PBSX prophage }\end{array}$

cdD 304 L-alanoyl-D-glutamate peptidase

ydcM 531 immunity region protein in prophage

yhgE 1090 phage infection protein

$\begin{array}{lll}\text { yjbJ } & 1235 & \text { lytic transglycosylase } \\ \text { yjaB } & 1318 \text { phage-related replication protein }\end{array}$

$\begin{array}{lll}\text { yjaB } & 1318 & \text { phage-related replication } \\ \text { ymaC } & 1863 \text { phage-related protein }\end{array}$

$y \mathrm{maC} 1863$ phage-related protein

ymfD 1755 phage-related protein

yobO 2075 phage-related pre-neck appendage protein

yokA 2284 DNA recombinase

yokL 2274 phage-related protein

yolB 22272 phage

yomJ 2248 phage-related immunity protein

yomP 2243 phage-related protein

$\begin{array}{lll}\text { yomR } & 2242 & \text { phage-related protein } \\ \text { yomS } & 2241 \text { phage-related lytic exoenzym }\end{array}$

yogD 2200 phage-related DNA-binding protein anti-repressor

yoqZ 2190 phage-related protein

(2700 phe

yaal 2696 phage related protein

yqaK 2695 phage-related protein

yqaM 2694 phage-related protein

yaaO 2692 phage-related protein

yqaS 2690 phage-related terminase small subunit

2689 phage-related terminase large subunit

Yab 2688 phage-related protein

2683 phage-related protein

yabH 2682 phage-related protein

yqbl 2681 phage-rele proten

yqbJ 2681 phage-related protei

yqbK 2680 phage-related protein

yqbL 2679 phage-related protein

yabN 2677 phage-related protein

yabO 2677 phage-related proten

YqbP 2672 phage-related protein

yqbQ 2671 phage-related protein

$q b R \quad 2670$ phage-related protein

qbS 2670 phage-related protein

gab 2670 phage-related protel

yacC 2668 phage-related protein

YacD 2667 phage-related protein

YacE 2666 phage-related protein

yqxG 2666 phage-related lytic exoenzyme

yqxH 2665 holin

IV.5 TRANSPOSONAND IS

$\begin{array}{lll}y d c P & 533 & \text { transposon protein } \\ y d c Q & 533 & \text { transposon }\end{array}$

$y d c R \quad 535$ transposon protein

$y d d B \quad 537$ transposon protei

yddE 538 transposon protein

$y d d H \quad 544$ transposon protein

yefB 739 site-specific recombinase

$\begin{array}{lll}\text { yefC } & 739 & \text { resolvase } \\ \text { yneB } & 1918 & \text { resonase }\end{array}$

yocA 2085 transposon-related protein

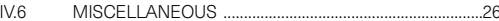

bex 2610 GTP-binding protein

$\begin{array}{lll}C S D A & 3614 & \text { putative membrane proten } \\ C S f B & 36 & \sigma^{F} \text {-transcribed }\end{array}$

ctaG $\quad 1564$ function unknown

eag 1430 small membrane protein

MmgE 2509 function unknown

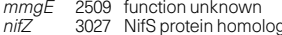

sapB 726 mutant activates alkaline phosphatase during

sbp 1595 small basic protein

veg 53 function unknown

$\begin{array}{lll}\text { yacl } & 102 & \text { creatine kinase } \\ \text { ybaL } & 157 & \text { ATP-binding Mrp-like protein }\end{array}$

$\begin{array}{lll}y c b U & 287 & \text { ATfS protein homologue }\end{array}$

yerN 730 pett12-like

yhdT 1035 hemolysin

yheG 1049 calcium-binding protein

yp/Q 2295 hemolysin III homologue

yqx 2523 hemolysin-like

yrvo 2811 NifS protein homologue

yuaG 3181 epidermal surface antigen

yurV 3357 NifU protein homologue

$\begin{array}{lll}\text { yurW } & 3358 & \text { NifS protein homologue } \\ \text { yutl } & 3309 & \text { Nifu protein homologue }\end{array}$

\section{SIMILAR TO UNKNOWN PROTEINS 668}

$3^{\underline{v}}$

FROM B. SUBTILIS

FROM OTHER ORGANISMS .491 